\title{
LQR Robust Control for Active and Reactive Power Tracking of a DFIG based WECS
}

\author{
New LMI Formulation based on Time Varying Lyapunov Candidate Function
}

\author{
Sana Salhi ${ }^{1}$, Salah Salhi ${ }^{2}$ \\ Laboratoire Analyse, Conception et Commande des Systèmes (LR11ES20) \\ Université de Tunis El Manar, Ecole Nationale d'Ingénieurs de Tunis \\ Tunis, Tunisia
}

\begin{abstract}
This research work sets forward a new formulation of Linear Quadratic Regulator problem (LQR) applied to a Wind Energy Conversion System (WECS). A new necessary and sufficient condition of Lyapunov asymptotic stability is also established. The problem is mathematically described in form of Linear Matrix Inequalities (LMIs). The considered WECS is based on a Doubly Fed Induction Generator (DFIG). An appropriate Linear Parameter Varying (LPV) model is designed. This model stands for a realistic representation of the randomly time varying wind velocity. Stability and robustness of the controller over the admissible values of time varying parameter are investigated. The newly lifted Lyapunov condition gives less conservative conditions for LMI approach in case of parameterdependent Lyapunov functions PDLF. The considered PDLF has the same variation dynamics as the system matrix. The intrinsic objective for our research is to offer more freedom degrees to the control problem and to improve the efficiency of the controller in case of uncertainties or parametric variations. The performances of the proposed theorems are validated to achieve active and reactive powers tracking of the WECS over the admissible range of wind speeds. The interesting features of the proposed solution are the simpler implementation and the larger robustness margin. It also has the advantage of providing a linear control to the considered nonlinear system without resorting to linearization. The LMIs implementation is performed on Yalmip Matlab toolbox. The proposed controller is verified on a Matlab Simulink emulator. This work presents an extension of the LQR control problem to LPV systems.
\end{abstract}

Keywords-LQR robust tracking; LPV system; lyapunov stability; LMI; DFIG based wind energy conversion systems; optimal control

\section{INTRODUCTION}

In recent years, the growing global energy needs and the permanent increase in the fossil fuels costs stand for the main concerns inciting a big interest in renewable energy harvesting. Among the existing resources, wind energy has attracted the attention of scientists and whetted their interest. In fact, it is one of the cleanest renewable resources [1-3]. Wind energy produces no greenhouse gas emissions and is much available. Several wind turbine technologies have emerged [4]. DFIG based one proves to be the most advantageous. It operates at a wide range of wind speeds. It provides higher energy capture. In addition, the DFIG allows a decoupled control of active and reactive power thanks to its Rotor Side Converter (RSC), and provides a constant DC voltage control thanks to its Grid Side Converter (GSC) [5-6].

The control and the functioning of DFIG based WECS presents some challenges due to the interaction of electrical and mechanical subsections [7]. The stability of the gridconnected system is one of the most significant challenges that is raised due to the nonlinear and stochastic nature of wind speed. Enhancement of scientific research in this context, have significantly improved the exploitation of the good points of DFIG based WECS [8]. Among the existing control techniques, the classical PI gives satisfactory performances in several control applications. However, this controller has many limitations mainly in case of severe parameters variations [4] [9]. In an attempt to overcome the PI limitations, such nonlinear control as sliding mode and backstepping have invaded the research laboratories. The main advantage of these techniques is that the control law is able to ensure at the same time satisfactory tracking performances and stability of the system [9-14]. However, robustness of these controllers are mostly evaluated in different constant values of the varying parameters. This implies that none of these control strategies takes into consideration the variation dynamics of the systems parameters. In addition, despite their good tracking performances, none of these controllers gives a good trade-off between the regulation and the control energy. Therefore, new methods based on optimal control theory have been investigated. The objective is to achieve good tracking performances with a better control energy efficiency. Taking advantage of the LQR robustness and availability to MIMO systems such as DFIG [15-17], this optimal controller is used to improve the dynamic response, the stability and the robustness of the control system against parameters variations. The authors of [18-23] have proposed different LQR control schemes for the considered system. These presented methods are mainly based either on a Linearized Time Invariant (LTI) model or on a small signal model of the system. However, such representations do not depict the real dynamics of the WECS. Furthermore, the control law is typically obtained through solving Riccati equation or based on quadratic stability Lyapunov theory. In both cases, the control problem is unfeasible unless a unique constant riccati or corresponding Lyapunov function is found. This makes the presented solutions conservative. 
This paper proposes a new LQR control scheme for DFIG active and reactive powers tracking. An appropriate LPV model that describes the time varying dynamics of the system is established. A new LMI formulation of the asymptotic Lyapunov stability condition based on the results of [24] is enunciated. The tracking performance of the non-conservative proposed method is proved. Robustness of the obtained controller over all the admissible range of parameters variations is verified. It is also shown that the proposed control scheme can significantly improve the stability of the system.

The remainder of this work is presented as follows. Section II, presents the state of the art of the considered DFIG based WECS. Section III raises the control problem. An appropriate system model suitable for the control objectives is identified. Section IV, enunciates a new formulation of the Lyapunov asymptotic stability condition based on mathematical relaxation techniques. Then a new LMI formulation of the robust LQR compensator is introduced. Section V, exhibits the simulation results and verifies the viability of the proposed method. Conclusion of this investigation is displayed in the last section.

\section{SYSTEM MODELLING}

The studied DFIG based WECS has the structure presented in Fig. 1. On the one hand, the wind generator is coupled to the wind turbine through a gearbox. On the other hand, the stator has a direct connection to the grid. The rotor is interfaced through a variable frequency back-to-back converter. The most important advantage of this technology is that it allows a decoupled control of active and reactive powers through the RSC and provides a constant voltage control on the DC link through the GSC. The structure of this kind of wound-rotor generator allows the WECS to operate at a variable speed range beyond synchronism

\section{A. The Wind Turbine Model}

The wind power available to a wind turbine is given by the following equation [25-26]:

$$
P_{\text {wind }}=\frac{1}{2} \rho \pi R^{2} V^{3}
$$

where $\rho$ is the air density, $R$ is the turbine radius and $V$ is the wind velocity. However, according to Betz's law, the real aerodynamic power captured by the generator is:

$$
P_{\text {mec }}=C_{p} P_{\text {wind }}=\frac{1}{2} C_{p} \rho \pi R^{2} V^{3}
$$

$C_{p}$ is the power coefficient. It is in function of the blade pitch angle $\beta$ and the tip speed ratio $\lambda$ such as:

$$
\lambda=\frac{\Omega_{t u r b} V}{R}
$$

$\Omega_{\text {turb }}$ is the mechanical speed of the low-speed shaft. The relation between $\Omega_{\text {turb }}$ and the mechanical speed of the highspeed shaft $\Omega_{m e c}$ is given by equation (4):

$$
\Omega_{\text {mec }}=G \Omega_{\text {turb }}
$$

$G$ is the gearbox ratio. The electrical speed of the rotor $\omega_{r}$ is related to $\Omega_{m e c}$ as follows:

$\Omega_{m e c}=\frac{\omega_{r}}{n_{p}}$

$n_{p}$ is the number of pole pairs. We consider the case of one pole pair machine and the angular speed frequency of the rotor currents is $\omega_{2}$ :

$\omega_{2}=\omega_{s}-\omega_{r}$

$\omega_{s}$ is the angular speed frequency of the stator currents. $C_{p}$ is defined as follows:

$$
\begin{gathered}
C_{p}(\lambda, \beta)=c_{1}\left(\frac{c_{2}}{\lambda_{i}}-c_{3} \beta-c_{4} \beta^{c_{5}}-c_{6}\right) \exp \left(\frac{-c_{7}}{\lambda_{i}}\right) \\
\lambda_{i}=\left[\left(\frac{1}{\lambda+c_{8} \beta}\right)-\left(\frac{c_{9}}{\beta^{3}+1}\right)\right]^{-1}
\end{gathered}
$$

The power coefficient is specific for each WECS and it is relevant in the efficiency study of a wind turbine. The characteristic of $C_{p}$ for different values of $\beta$ and $\lambda$ is illustrated in Fig. 2. The turbine parameters $c_{i}$ with $i=1$...9 are given in Table 2. Tables 1 and 3 show respectively the turbine and the generator parameters.

TABLE I. WIND TURBINE PARAMETERS

\begin{tabular}{|l|l|}
\hline Value & Signification \\
\hline $\mathrm{R}=13.5$ & Wind turbine radius $(\mathrm{m})$ \\
\hline $\boldsymbol{\rho}$ & Air density $\left(\mathrm{Kg} / \mathrm{m}^{2}\right)$ \\
\hline $\mathrm{G}$ & Gear box ratio \\
\hline
\end{tabular}

TABLE II. POWER COEFFICIENT PARAMETERS

\begin{tabular}{|l|l|l|l|l|l|}
\hline $\mathbf{C}_{\mathbf{1}}$ & $\mathbf{C}_{\mathbf{2}}$ & $\mathbf{C}_{\mathbf{3}}$ & $\mathbf{C}_{\mathbf{4}}$ & $\mathbf{C}_{\mathbf{5}}$ & $\mathbf{C}_{\mathbf{6}}$ \\
\hline 0.5176 & 116 & 0.4 & 5 & 21 & 0.0068 \\
\hline
\end{tabular}




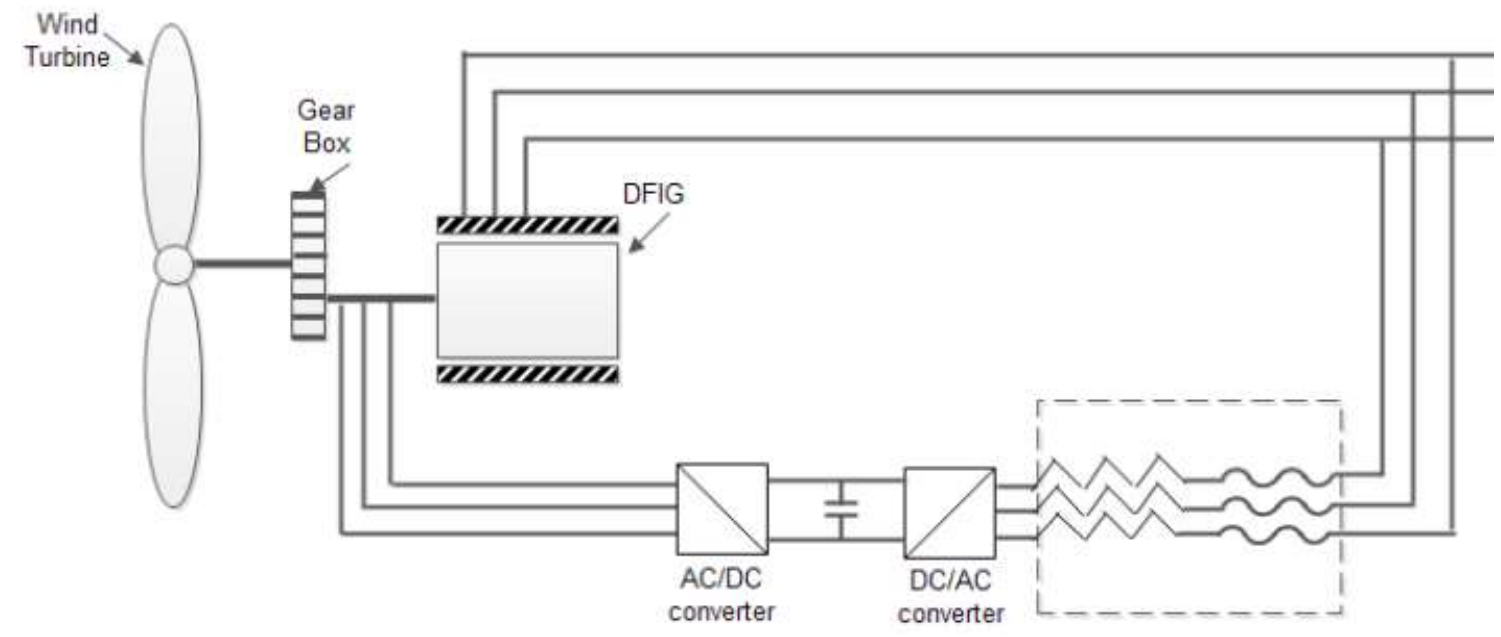

Fig. 1. Variable Speed Wind Turbine based on DFIG..

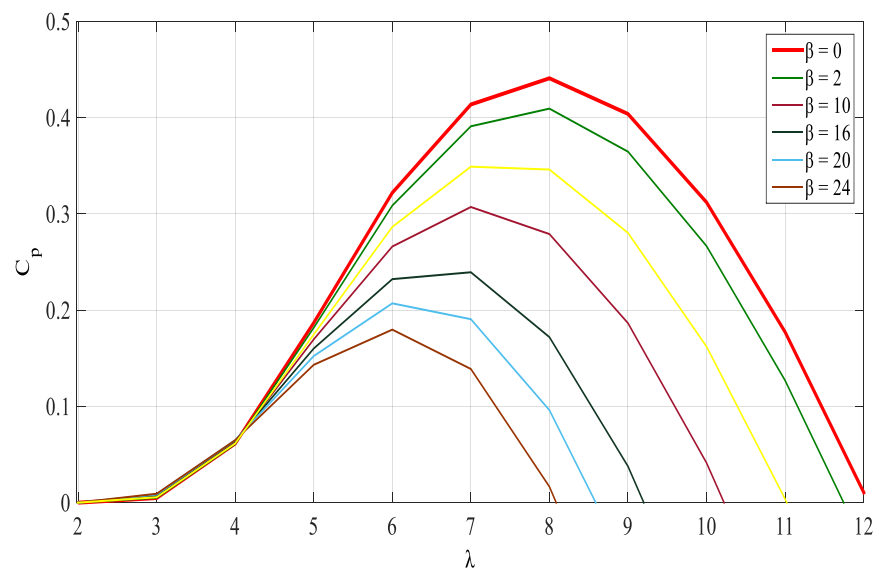

Fig. 2. Power Coefficient $\mathrm{Cp}(\beta, \lambda)$.

TABLE III. DFIG PARAMETERS

\begin{tabular}{|c|c|}
\hline Value & Signification \\
\hline $\mathrm{Rs}=0.0089$ & Stator resistance $(\Omega)$ \\
\hline $\mathrm{Rr}=0.0137$ & Rotor resistance $(\Omega)$ \\
\hline $\mathrm{Ls}=0.0128$ & Stator inductance $(\mathrm{H})$ \\
\hline $\mathrm{Lr}=0.0128$ & Rotor inductance $(\mathrm{H})$ \\
\hline $\mathrm{Lm}=0.0127$ & Mutual inductance $(\mathrm{H})$ \\
\hline $\mathrm{np}=1$ & Number of pair of poles \\
\hline $\mathrm{U}=690$ & $\begin{array}{l}\text { Nominal stator phase-to-phase } \\
\text { voltage }(\mathrm{V})\end{array}$ \\
\hline $\mathrm{f}$ & $\begin{array}{l}\text { Nominal stator current } \\
\text { frequency }(\mathrm{Hz})\end{array}$ \\
\hline $\mathrm{J}$ & Turbine shaft inertia \\
\hline
\end{tabular}

\section{B. The DFIG model}

The DFIG model is commonly given by the following $d-q$ frame equations:

- Electrical equations:

$V_{s d}=-R_{s} I_{s d}-\dot{\varphi}_{s d}+\omega_{s} \varphi_{s q}$

$V_{s q}=-R_{s} I_{s q}-\dot{\varphi}_{s q}-\omega_{s} \varphi_{s d}$

$V_{r d}=R_{r} I_{r d}+\dot{\varphi_{r d}}-\left(\omega_{s}-\omega_{r}\right) \varphi_{r q}$

$V_{r q}=R_{r} I_{r q}+\dot{\varphi}_{r q}+\left(\omega_{s}-\omega_{r}\right) \varphi_{r d}$

- Magnetic equations:

$\varphi_{s d}=L_{s} I_{s d}+L_{m} I_{r d}$

$\varphi_{s q}=L_{s} I_{s q}+L_{m} I_{r q}$

$\varphi_{r d}=L_{r} I_{r d}+L_{m} I_{s d}$

$\varphi_{r q}=L_{r} I_{r q}+L_{m} I_{s q}$

The rotor shaft dynamics are described by the following equation:

$J \frac{d \Omega_{m e c}}{d t}=C_{m}-C_{e m}$

$C_{m}$ and $C_{e m}$ are respectively the mechanical torque of the turbine and the generator electromagnetic torque. 


$$
\begin{gathered}
C_{m}=\frac{P_{m e c}}{\Omega_{m e c}} \\
C_{e m}=-\frac{3}{2} n_{p} \frac{L_{m}}{L_{s}}\left(I_{r d} \varphi_{s q}-I_{r q} \varphi_{s d}\right)
\end{gathered}
$$

A vector control is necessary in order to provide a decoupled control of the electromagnetic torque and the stator flux. The orientation of the Park frame according to the stator voltage axis leads to the following assumptions:

$$
\begin{aligned}
& \varphi_{s d}=L_{s} I_{s d}+L_{m} I_{r d} \approx \varphi_{s} \\
& \varphi_{s q}=L_{s} I_{s q}+L_{m} I_{r q} \approx 0 \\
& V_{s d}=0 \\
& V_{s q}=V_{g \text { max }}=-\omega_{s} \varphi_{s}
\end{aligned}
$$

$V_{g \text { max }}$ is the magnitude of the grid voltage:

$$
V_{g \max }=V_{s} \sqrt{2}
$$

Based on these assumptions, the connection between stator and rotor currents are given as follows:

$$
\begin{aligned}
& I_{s d}=\frac{\varphi_{s}}{L_{s}}-\frac{L_{m}}{L_{s}} I_{r d} \\
& I_{s q}=-\frac{L_{m}}{L_{s}} I_{r q}
\end{aligned}
$$

\section{CONTROL Problem Formulation}

This subsection defines the control objective and describes the considered approach to formulate the control problem.

\section{A. Control Objective}

The WECS fills the grid with active and reactive power through its stator windings. In a variable speed concept, for each wind velocity, the system can operate at a wide range of mechanical speeds. This implies that different values of wind power can be extracted. Fig. 3 shows that in an uncontrolled operation mode and for a constant wind velocity, the maximum power point does not correspond to the maximum mechanical rotational speed value. Optimization algorithms have been developed in this sense in order to impel the wind turbine system to track the maximum power point trajectory [28-29]. Fig. 3 Shows the Maximum Power Points curve (bold line) for different values of wind speeds.

In this work, based on the Maximum Power Point Tracking results, we manage to achieve a robust tracking of both active and reactive powers of the WECS by means of a stabilizing LQR controller. The control scheme that we intend to establish is that of a state feedback compensator based on Lyapunov theory. Robustness and tracking performances of the regulator will be verified over the whole time varying parameter's admissible range. Generally, LQR controllers for LPV systems such as DFIG are mostly based either on linearized model of the system or through interpolation of different control gains obtained at different operating points. The abovementioned methods present some weaknesses related to linearization inaccuracies mainly in case of parameters variations and deficiencies in interpolation assumptions. Our contribution consists in deriving a robust $\mathrm{LQR}$ controller based on a realistic Linear Parameter Varying model of the system.

\section{B. Model for Controller Design}

The LPV model considered for the design of the control law has the following shape:

$$
\left\{\begin{array}{c}
\dot{x}(t)=A(\delta(t)) x(t)+B(\delta(t)) u(t) \\
x=\left(\begin{array}{c}
I_{r d} \\
I_{r q}
\end{array}\right) ; u=\left(\begin{array}{c}
V_{s d} \\
V_{s q} \\
V_{r d} \\
V_{r q}
\end{array}\right)
\end{array}\right.
$$

Where the notations used in (21) are as follows:

$$
\begin{array}{r}
x \in \square^{n}: \text { state vector } \\
u \in \square^{m}: \text { control inputs } \\
\delta(t)=\left[\delta_{1}(t), \delta_{2}(t) \ldots \delta_{r}(t)\right]^{T} \in \square^{r}
\end{array}
$$$$
\text { :time-varying }
$$
parametric uncertainty.

The state space matrices $A(\delta(t))$ and $B(\delta(t))$ depend affinely on $\delta(t)$. The real parameter $\delta(t)$ is not real-time measurable but it varies in a defined polytope $\Theta$ of $N \in 2^{r}$ vertices. The signification of $\delta(t)$ in function of the system parameters will be revealed later.

This paper investigates power flux control of the wind system. Therefore, the choice of the state model is based on the expressions of active and reactive powers equations in a Park frame:

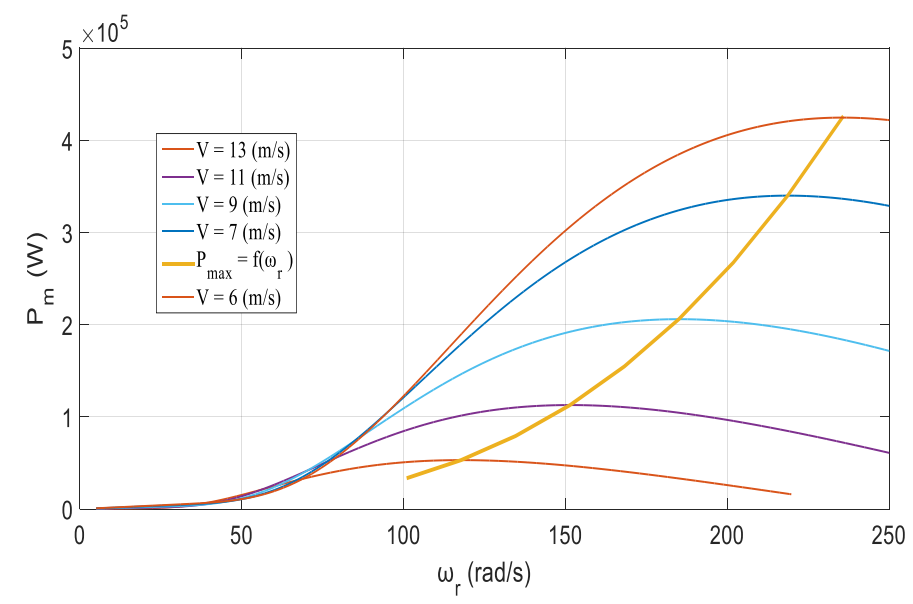

Fig. 3. Maximum Operation Power Points. 


$$
\begin{aligned}
& P_{s}=\frac{3}{2}\left(V_{s d} I_{s d}+V_{s q} I_{s q}\right) \\
& Q_{s}=\frac{3}{2}\left(V_{s q} I_{s d}-V_{s d} I_{s q}\right)
\end{aligned}
$$

Introducing the vector control (equations (18), (19) and (20)), equations (22) and (23) become:

$$
\begin{aligned}
P_{s} & =-\frac{3}{2} V_{g \max } \frac{L_{m}}{L_{s}} I_{r q} \\
Q_{s} & =-\frac{3}{2} V_{g \max } \frac{L_{m}}{L_{s}} I_{r d}+\frac{3}{2} \frac{V_{g \max }^{2}}{\omega_{s} L_{s}}
\end{aligned}
$$

Equations (24) and (25), show that active and reactive powers tracking can be performed through rotor currents control. These latter can be controlled through direct and quadratic components of stator and rotor voltages. In order to define the relationship between these parameters, let us start with equations (10) and (11) where rotor flux can be replaced according to (20):

$$
\begin{aligned}
& \varphi_{r d}=L_{r} I_{r d}+L_{m}\left(\frac{\varphi_{s}}{L_{s}}-\frac{L_{m}}{L_{s}}\right) I_{r d} \\
& \varphi_{r d}=\left(L_{r}+\frac{L_{m}^{2}}{L_{s}}\right) I_{r d}+\frac{L_{m}}{L_{s}} \varphi_{s} \\
& \varphi_{r q}=L_{r} I_{r q}-\frac{L_{m}^{2}}{L_{s}} I_{r q} \\
& \varphi_{r q}=\left(L_{r}+\frac{L_{m}^{2}}{L_{s}}\right) I_{r q}
\end{aligned}
$$

Replacing (26) and (27) in (10) and (11) gives:

$$
\begin{gathered}
V_{r d}=R_{r} I_{r d}+\frac{d}{d t}\left(\sigma_{L r} I_{r d}+\frac{L_{m}}{L_{s}} \varphi_{s}\right) \\
+\left(\omega_{s}-\omega_{r}\right) \sigma_{L r} I_{r q} \\
V_{r q}=R_{r} I_{r q}+\frac{d}{d t}\left(\sigma_{L r} I_{r q}\right) \\
-\left(\omega_{s}-\omega_{r}\right)\left(\sigma_{L r} I_{r d}+\frac{L_{m}}{L_{s}} \varphi_{s}\right)
\end{gathered}
$$

with:

$$
\sigma_{\mathrm{Lr}}=\left(\mathrm{L}_{\mathrm{r}}+\frac{\mathrm{L}_{\mathrm{m}}^{2}}{\mathrm{~L}_{\mathrm{s}}}\right)
$$

If a constant load voltage is considered, $\varphi_{s}$ is constant as well. Hence, (28) and (29) become:

$V_{r d}=R_{r} I_{r d}+\sigma_{L r} \frac{d}{d t}\left(I_{r d}\right)+\sigma_{L r}\left(\omega_{s}-\omega_{r}\right) I_{r q}$

$$
\begin{gathered}
V_{r q}=R_{r} I_{r q}+\sigma_{L r} \frac{d}{d t}\left(I_{r q}\right)-\sigma_{L r}\left(\omega_{s}-\omega_{r}\right) I_{r d} \\
-\left(\omega_{s}-\omega_{r}\right) \frac{L_{m}}{L_{s}} \varphi_{s}
\end{gathered}
$$

Hence, equation (24) is obtained by replacing $\varphi_{s}$ in (31) as in (18). Thus, the derivatives of direct and quadratic components of the rotor current are given as follows:

$$
\begin{gathered}
\frac{d}{d t}\left(I_{r d}\right)=-\frac{R_{r}}{\sigma_{L r}} I_{r q}-\left(\omega_{s}-\omega_{r}\right) I_{r d}+\frac{V_{r d}}{\sigma_{L r}} \\
\frac{d}{d t}\left(I_{r q}\right)=\left(\omega_{s}-\omega_{r}\right) I_{r d}-\frac{R_{r}}{\sigma_{L r}} I_{r q} \\
+\frac{L_{m}}{L_{s} \omega_{s} \sigma_{L r}}\left(\omega_{s}-\omega_{r}\right) V_{s q}+\frac{V_{r q}}{\sigma_{L r}}
\end{gathered}
$$

From (32) and (33), the state and the input matrix in (21) are respectively deduced as in (34) and (35):

$$
\begin{aligned}
& A\left(\omega_{r}(t)\right)=\left(\begin{array}{ll}
-\left(\omega_{s}-\omega_{r}(t)\right) & -\frac{R_{r}}{\sigma_{L r}} \\
\left(\omega_{s}-\omega_{r}(t)\right) & -\frac{R_{r}}{\sigma_{L r}}
\end{array}\right) \\
& B\left(\omega_{r}(t)\right)=\left(\begin{array}{llll}
0 & 0 & \frac{1}{\sigma_{L r}} & 0 \\
0 & \frac{L_{m}}{L_{s} \cdot \omega_{s} \cdot \sigma_{L r}} \cdot\left(\omega_{s}-\omega_{r}(t)\right) & 0 & \frac{1}{\sigma_{L r}}
\end{array}\right)
\end{aligned}
$$

$\omega_{s}$ is the stator angular speed frequency. Assuming that the studied WECS is grid connected then $\omega_{s}$ is constant:

$\omega_{s}=2 \pi f$

with $f$ is the grid frequency.

The analogy between matrices in (21), (34) and (35) is deduced. The electrical speed of the rotor $\omega_{r}(t)$ is the timevarying parametric uncertainty of the DFIG. In the general case of an LPV system, $\delta(t)$ must range as follows:

$-1 \leq \delta(t) \leq 1$

However, the rotor electrical speed of a DFIG varies of $\pm 30 \%$ around $\omega_{s}$. Therefore, in our case, a normalization step is necessary. It consists in defining a new time varying parameter $\delta(t)$ for (34) and (35) that satisfies (37) such that:

$\omega_{r}(t)=\omega_{r 0}+\omega . \delta(t)$

with

$\omega_{r 0}=\frac{\omega_{r \text { max }}+\omega_{r \text { min }}}{2}$ 
and

$\omega=\frac{\omega_{r \max }-\omega_{r \min }}{2}$

Based on these assumptions, the normalized LPV affine model is deduced. The normalization concept is detailed in [30]. The state matrices of the normalized model have the following form:

$$
\begin{aligned}
& A(\delta(t))=A_{0}+\delta(t) A_{1} \\
& B(\delta(t))=B_{0}+\delta(t) B_{1}
\end{aligned}
$$

The normalized LPV affine plant is then given by the following expression:

$$
\begin{gathered}
M(\delta(t))=M_{0}+\delta(t) M_{1} \\
M_{0}=\left[\begin{array}{cc}
A_{0} & B_{0} \\
C & \mathrm{D}
\end{array}\right] ; M_{1}=\left[\begin{array}{cc}
A_{1} & B_{1} \\
0 & 0
\end{array}\right]
\end{gathered}
$$

$\mathrm{C}$ and D are constant and they respectively stand for the output and the feedforward matrix. The control objective involves the states feedback, therefore only state matrix $A(\delta(t))$ and input matrix $B(\delta(t))$ are concerned. The conversion of (42) into a polytopic LPV structure is more convenient for the formulation and the implementation of convex optimization problems. As in [30], the new polytopic model is obtained from (42) based on the following changes:

$$
\begin{gathered}
M_{1}^{s}=M_{0}+\underline{\delta} M_{1} \\
M_{1}^{s}=\left[\begin{array}{ll}
A_{0} & \mathrm{~B}_{0} \\
C & \mathrm{D}
\end{array}\right]+\underline{\delta}\left[\begin{array}{ll}
A_{1} & \mathrm{~B}_{1} \\
0 & 0
\end{array}\right] \\
M_{2}^{s}=M_{0}+\bar{\delta} M_{1} \\
M_{2}^{s}=\left[\begin{array}{ll}
A_{0} & \mathrm{~B}_{0} \\
C & \mathrm{D}
\end{array}\right]+\bar{\delta}\left[\begin{array}{ll}
A_{1} & \mathrm{~B}_{1} \\
0 & 0
\end{array}\right]
\end{gathered}
$$

and

$\alpha_{1}(t)=\frac{\bar{\delta}-\delta(t)}{\bar{\delta}-\underline{\delta}} ; \alpha_{2}(t)=\frac{\delta(t)-\underline{\delta}}{\bar{\delta}-\underline{\delta}}$

$\bar{\delta}$ and $\underline{\delta}$ are the maximal and minimal values of $\delta(t)$. $\alpha(t)=\left[\alpha_{1}(t), \alpha_{2}(t)\right]^{T} \in \square^{2}$ is the polytopic time-varying uncertain parameter. Then the LPV polytopic plant is derived as follows:

$$
\begin{gathered}
M(\alpha(t))=\alpha_{1}(t) M_{1}^{s}+\alpha_{2}(t) M_{2}^{s} \\
M(\alpha(t))=\alpha_{1}(t)\left[\begin{array}{ll}
A_{0} & \mathrm{~B}_{0} \\
C & \mathrm{D}
\end{array}\right]+\alpha_{1}(t) \underline{\delta}\left[\begin{array}{ll}
A_{1} & \mathrm{~B}_{1} \\
0 & 0
\end{array}\right] \\
+\alpha_{2}(t)\left[\begin{array}{ll}
A_{0} & \mathrm{~B}_{0} \\
C & \mathrm{D}
\end{array}\right]+\alpha_{2}(t) \bar{\delta}\left[\begin{array}{ll}
A_{1} & \mathrm{~B}_{1} \\
0 & 0
\end{array}\right]
\end{gathered}
$$

The polytopic LPV structure of (42) is given by:

$$
\begin{gathered}
\dot{x}(t)=A_{p}(\alpha(t)) x(t)+B_{p}(\alpha(t)) u(t) \\
A_{p}(\alpha(t))=\alpha_{1}(t) A_{p 1}+\alpha_{2}(t) A_{p 2} \\
B_{p}(\alpha(t))=\alpha_{1}(t) B_{p 1}+\alpha_{2}(t) B_{p 2} \\
0 \leq \alpha_{i} \leq 1 \\
\sum \alpha_{i}=1
\end{gathered}
$$

Such that:

$$
\begin{aligned}
& A_{p 1}=A_{0}+\underline{\delta} A_{1} \\
& A_{p 2}=A_{0}+\bar{\delta} A_{1} \\
& B_{p 1}=B_{0}+\underline{\delta} B_{1} \\
& B_{p 2}=B_{0}+\bar{\delta} B_{1}
\end{aligned}
$$

The state matrix $A_{p}(\alpha(t))$ and $B_{p}(\alpha(t))$ have a polytopic dependence on the newly defined time-varying parameter $\alpha(t)$.

This work focuses on a tracking control problem. Accordingly, the tracking error is considered for the controller synthesis. In the next paragraph, the error system is modelled.

\section{The Error Model Synthesis}

The main objective is to achieve robust active and reactive powers tracking to the studied WECS. The robustness of the controller refers to its availability for the entire convex polytope that contains the admissible parameters variations of the system. The control diagram in Fig. 4 describes the proposed control scheme. From (24) and (25), one can conclude that impelling the system to operate at desired values of $P_{s}$ and $Q_{s}$, means imposing a precise value of the couple $\left(I_{r q}, I_{r d}\right)$. In other words, for given values of $P_{\text {sref }}$ and $Q_{\text {sref }}$, the rotor must operate at a precise value of the couple ( $I_{r d_{r e f}}, I_{r q_{r e f}}$ ). This is equivalent to designing a controller that allows the following:

$$
\lim _{t \rightarrow \infty}\left(\begin{array}{c}
I_{r d}-I_{r d_{r e f}} \\
I_{r q}-I_{r q_{r e f}}
\end{array}\right)=\left(\begin{array}{l}
\mathrm{O} \\
\mathrm{O}
\end{array}\right)
$$

Accordingly, the error state space model that we provide in this chapter is obtained from the following assumptions:

$$
\begin{aligned}
e(t) & =x(t)-x_{r e f}(t) \\
\Rightarrow \dot{e}(t) & =\dot{x}(t)-\dot{x}_{r e f}(t)
\end{aligned}
$$

(49) is equivalent to (50):

$$
\begin{aligned}
\left(\dot{x}(t)-\dot{x}_{r e f}(t)\right) & =A_{p}(\alpha(t)) x(t)+B_{p}(\alpha(t)) u(t) \\
& -A_{p}\left(\alpha_{r e f}\right) x_{r e f}(t)-B_{p}\left(\alpha_{r e f}\right) u_{r e f}(t)
\end{aligned}
$$

Let (50) compute the dynamics of the error. For trajectory tracking, $e(t)$ is considerably small. In addition, by expanding, simplifying (50) and admitting that $\alpha(t)$ is its unique timevarying parameter, the error dynamic can be modelled as follows: 


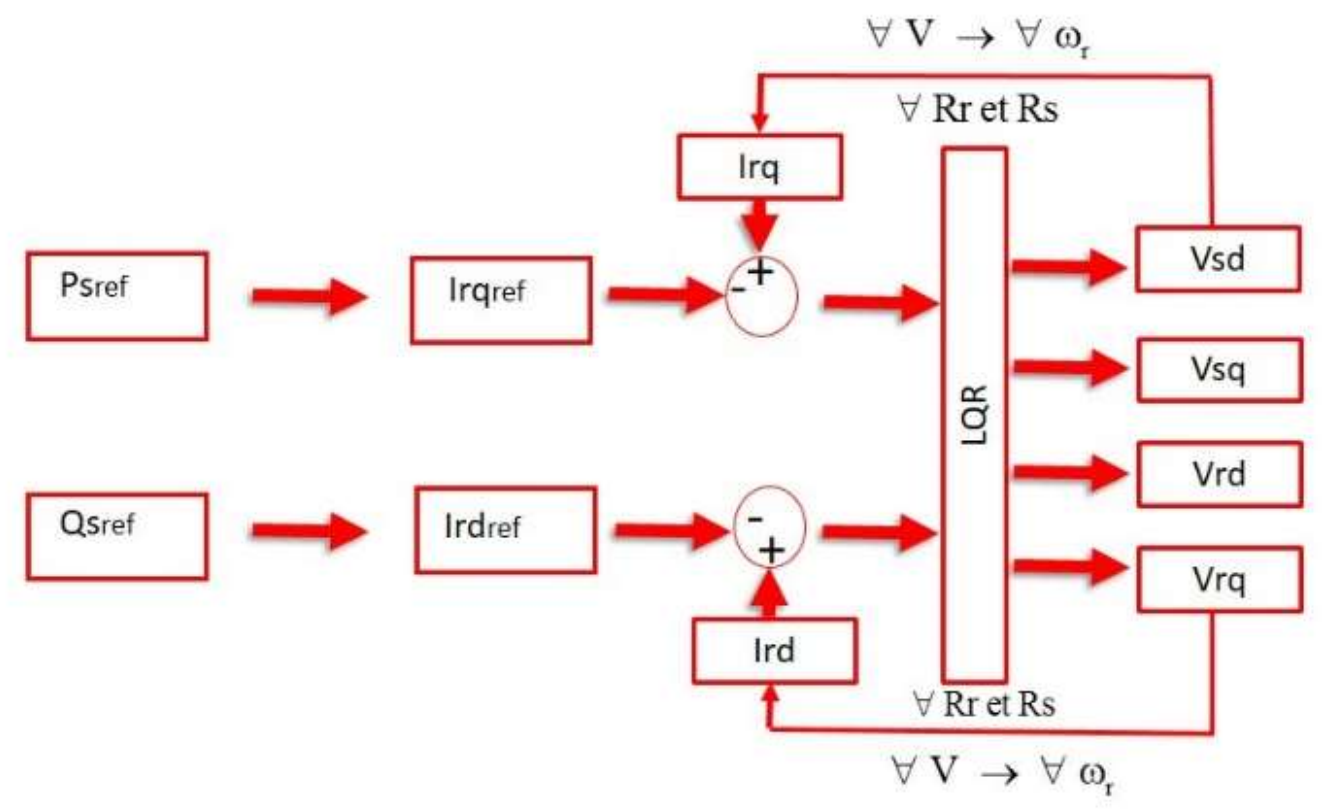

Fig. 4. LQR Control Diagram.

$\dot{e}(t)=A_{p}(\alpha(t)) e(t)+B_{p}(\alpha(t)) v(t)$

$v(t)=u(t)-u_{r e f}(t)$

Hence, the LQR state feedback control law is:

$v=K e$

Substituting back e and v, the focused control law becomes:

$u(t)=K\left(x(t)-x_{r e f}\right)+u_{r e f}$

$A_{p}(\alpha(t))$ and $B_{p}(\alpha(t))$ are respectively obtained from the difference between $A(\alpha(t))$ and $A\left(\alpha_{\text {ref }}\right)$, and $B(\alpha(t))$ and $B\left(\alpha_{r e f}\right) \alpha_{r e f}$ is derived from the reference value of $\omega_{r}$. The latter parameter is auto generated by a lookup table that gives for each desired value of power its corresponding optimal rotor electrical speed. In other words, a Maximum Power Point Tracking (MPPT) control can provide the optimal value of $\omega_{r}$ . The final polytopic LPV error model is obtained as well as (46) after normalization and polytopic conversion of its affine structure. Both controllability and observability are verified for the newly defined model (51). In the following chapter, the stability analysis of system (51) will be checked in order to validate the error model.

\section{LMI FORMULATION OF AN LQR STATE FEEDBACK CONTROL}

LMI approach is a convex optimization based method that aims at solving a set of linearly dependent equations. In the following subsections, we will adopt this approach in order to synthetize an optimal controller to the considered LPV system based on a new formulation of Lyapunov condition. The synthesis of a robust LQR regulator for (51) under a convex minimization problem is emphasized for both constant and time varying Lyapunov candidate matrices. The main objective is obviously the state space tracking controller synthesis for (21).

\section{A. LQR Robust Control Problem}

The LQR problem consists in finding the optimal state feedback control law $\mathrm{u}(\mathrm{t})=\mathrm{Kx}(\mathrm{t})$ that minimizes the quadratic performance index (55) [18]:

$\mathrm{J}=\int_{0}^{+\infty}\left(\mathrm{x}^{\mathrm{T}} \mathrm{Q} \mathrm{x}+\mathrm{u}^{\mathrm{T}} \mathrm{Ru}\right) \mathrm{dt}$

In closed loop (55) becomes:

$J=\int_{0}^{+\infty}\left(x^{\mathrm{T}} Q x+x^{\mathrm{T}} K^{\mathrm{T}} \mathrm{RKx}\right) \mathrm{dt}$

$J=\int_{0}^{+\infty}\left(X^{\mathrm{T}}\left(\mathrm{Q}+\mathrm{K}^{\mathrm{T}} \mathrm{R} \cdot \mathrm{K}\right) \mathrm{Xdt}\right.$

The trace operator allows: $\alpha^{\mathrm{T}} \mathrm{X} \beta=\operatorname{Tr}\left(\mathrm{X} \beta \alpha^{\mathrm{T}}\right)$. In this work, the control variable is expressed by the constant state feedback K Thus, (57) can be written as follows:

$$
\begin{aligned}
& J=\int_{0}^{+\infty} \operatorname{Tr}\left(Q+K^{\mathrm{T}} R K\right) \mathrm{xx}^{\mathrm{T}} \mathrm{dt} \\
& \mathbf{J}=\operatorname{Tr}\left(\mathrm{Q}+\mathrm{K}^{\mathrm{T}} \mathrm{RK}\right) \int_{0}^{\infty} \mathrm{xx}^{\mathrm{T}} \mathrm{dt} \\
& \mathbf{J}=\operatorname{Tr}\left(\mathrm{Q}+\mathrm{K}^{\mathrm{T}} \mathrm{RK}\right) \mathrm{P}
\end{aligned}
$$


Such that:

$\int_{0}^{\infty} \mathrm{x} \mathrm{x}^{\mathrm{T}} \mathrm{dt}=\mathrm{P}$

Otherwise:

$P=\int_{0}^{\infty} e^{(A+B K) t} x_{0} x_{0}^{T} e^{(A+B K)^{T} t} d t$

$\mathrm{P}$ is a definite positive symmetric matrix that will satisfy the Lyapunov stability condition [27-28].

\section{B. Robust Control Problem for a Constant Lyapunov Matrix}

$P$

Lyapunov theory states that the linear system (61) is quadratically stable if there exists a matrix $\mathrm{P}$ satisfying the quadratic function (62):

$\dot{x}(t)=A x(t)$

$\mathrm{V}(\mathrm{x})=\mathrm{x}^{\mathrm{T}} \mathrm{Px}>0 \quad \forall \mathrm{x} \neq 0$

With:

$\dot{\mathrm{V}}(\mathrm{x})=\mathrm{x}^{\mathrm{T}}\left(\mathrm{A}^{\mathrm{T}} \mathrm{P}+\mathrm{PA}\right) \mathrm{x}<0 \quad \forall \mathrm{x} \neq 0$

There must exist $\mathrm{P}>0$ to assure quadratic stability. The inequality (63) is an LMI since it contains linear dependence on the variable $\mathrm{P}$ and can be solved through convex optimization methods. In this study, the LMI formulation of the LQR problem into a convex optimization one is adapted from [31]. The LQR optimal control law must minimize the following cost:

$$
\min _{\mathrm{P}, \mathrm{K}} \operatorname{Tr}(\mathrm{QP})+\operatorname{Tr}\left(\mathrm{R}^{1 / 2} \mathrm{KPK}^{\mathrm{T}} \mathrm{R}^{1 / 2}\right)
$$

Subject to:

$$
(\mathrm{A}+\mathrm{BK}) \mathrm{P}+\mathrm{P}(\mathrm{A}+\mathrm{BK})^{\mathrm{T}}+\mathrm{x}_{0} \mathrm{x}_{0}{ }^{\mathrm{T}}<0
$$

The inequality (65) is equivalent to the Lyapunov stability condition in closed loop. Nevertheless, inequalities (64) and (65) are not linear because they involve the multiplication of variables $\mathrm{P}$ and $\mathrm{K}$. Thus, a new slack variable $Y=K P$ is introduced so that (64) and (65) become:

$\min _{\mathrm{P}, \mathrm{K}} \operatorname{Tr}(\mathrm{QP})+\operatorname{Tr}\left(\mathrm{R}^{1 / 2} \mathrm{YP}^{-1} \mathrm{Y}^{\mathrm{T}} \mathrm{R}^{1 / 2}\right)$

Subject to:

$$
\mathrm{AP}+\mathrm{PA}^{\mathrm{T}}+\mathrm{BY}+\mathrm{Y}^{\mathrm{T}} \mathrm{B}^{\mathrm{T}}+\mathrm{x}_{0} \mathrm{x}_{0}{ }^{\mathrm{T}}<0
$$

The nonlinearity in $\mathrm{R}^{1 / 2} \mathbf{Y P}^{-1} \mathrm{Y}^{\mathrm{T}} \mathrm{R}^{1 / 2}$ must also be eliminated by introducing a new slack variable $\mathrm{X}$ that satisfies:

$$
\mathrm{X}>\mathrm{R}^{1 / 2} \mathrm{KPK}^{\mathrm{T}} \mathrm{R}^{1 / 2}
$$

(68) can be decomposed by Schur complement under the following LMI form:

$$
\left[\begin{array}{ll}
\mathrm{X} & \mathrm{R}^{1 / 2} \mathrm{Y} \\
\mathrm{Y}^{\mathrm{T}} \mathrm{R}^{1 / 2} & \mathrm{P}
\end{array}\right]>0
$$

The inequality (67) is homogeneous on the matrices $\mathrm{P}$ and $\mathrm{Y}$. Otherwise for any matrices $\mathrm{P}^{*}$ and $\mathrm{Y}^{*}$ that satisfy this LMI, $\mu . P$ and $\mu . Y$, with $\mu>0$ will also fulfill the inequality. In this case there will not be a dependence between $\mathrm{K}=\mathrm{YP}^{-1}$ and $\mu$ [31]. Hence (67) is equivalent to $\mathrm{AP}+\mathrm{PA}^{\mathrm{T}}+\mathrm{BY}+\mathrm{Y}^{\mathrm{T}} \mathrm{B}^{\mathrm{T}}+\mathrm{I}<0$. Accordingly, the $\mathrm{LMI}$ formulation for the considered $\mathrm{LQR}$ problem is:

Subject to:

$$
\min _{\mathrm{P}, \mathrm{Y}, \mathrm{X}} \operatorname{Tr}(\mathrm{QP})+\operatorname{Tr}(\mathrm{X})
$$

$\mathrm{AP}+\mathrm{PA}^{\mathrm{T}}+\mathrm{BY}+\mathrm{Y}^{\mathrm{T}} \mathrm{B}^{\mathrm{T}}+\mathrm{I}<0$

$\left[\begin{array}{ll}\mathrm{X} & \mathrm{R}^{1 / 2} \mathrm{Y} \\ \mathrm{Y}^{\mathrm{T}} \mathrm{R}^{1 / 2} & \mathrm{P}\end{array}\right]>0$

With:

$\mathrm{K}=\mathrm{YP}^{-1}$

\section{LQR Robust Control Problem for a Time Varying Lyapunov Candidate Matrix $P$}

The time derivative of the Lyapunov candidate matrix is non-null and expressed as follows [24]:

where $b, \dot{\alpha}_{i}(t), \sigma_{j}(t)$ and $\beta_{k}(t)$ are as in [24].

$$
\begin{gathered}
\dot{P}(\alpha(t))=\sum \dot{\alpha}_{i}(t) P_{i}=b \sum\left(\sigma_{j}(t)-\beta_{k}(t)\right) P_{i} \\
=b(P(\sigma(t))-P(\beta(t)))
\end{gathered}
$$

Thus, the LMI formulation of the LQR control problem under Lyapunov stability theory for our system is:

$$
\min _{\mathrm{P}, \mathrm{Y}, \mathrm{X}} \operatorname{Tr}(\mathrm{QP}(\alpha(\mathrm{t})))+\operatorname{Tr}(\mathrm{X}(\alpha(\mathrm{t})))
$$

Subject to:

$$
\begin{aligned}
& \quad \mathrm{A}(\alpha(\mathrm{t})) \mathrm{P}(\alpha(\mathrm{t}))+\mathrm{P}(\alpha(\mathrm{t})) \mathrm{A}(\alpha(\mathrm{t}))^{\mathrm{T}} \\
& +\mathrm{B}(\alpha(\mathrm{t})) \mathrm{KP}(\alpha(\mathrm{t}))+\mathrm{P}(\alpha(\mathrm{t})) \mathrm{K}^{\mathrm{T}} \mathrm{B}(\alpha(\mathrm{t}))^{\mathrm{T}} \\
& \quad+\mathrm{b}(\mathrm{P}(\sigma(\mathrm{t}))-\mathrm{P}(\beta(\mathrm{t})))+\mathrm{I}<0
\end{aligned}
$$

and

$$
\mathrm{X}(\alpha(\mathrm{t}))>\mathrm{R}^{1 / 2} \mathrm{KP}(\alpha(\mathrm{t})) \mathrm{K}^{\mathrm{T}} \mathrm{R}^{1 / 2}
$$

The first and the second inequalities of (75) corresponding respectively to the Lyapunov stability condition and Schur complement are non-linear. This non-linearity is due to the multiplication of both the dynamic matrix of the system and the controller gain by the Lyapunov candidate matrix. This non-linearity makes the resolution of this LMI problem complex and even impossible in the Yalmip toolbox employed 
in this work. Hence, the use of relaxation techniques is necessary to allow efficient solving of the considered LMI problem. In this context, our contribution in this work consists in enunciating a new LMI formulation of the Lyapunov asymptotic stability condition. This newly stated condition in Theorem 1 relaxes mathematical formulation of the problem and gives further freedom degree to the LMI system.

\section{Theorem 1:}

The linear system (51) is asymptotically stable in closed loop if there exists a sufficiently large positive scalar $\theta$, positive definite symmetric matrices $X_{L i} \in \square(n \times n)$, $\mathrm{X}_{\mathrm{Lj}} \in \square(\mathrm{n} \times \mathrm{n})$ and $\mathrm{X}_{\mathrm{Lk}} \in \square(\mathrm{n} \times \mathrm{n})$, and matrices $\mathrm{Y}$ and $\mathrm{G}$ of appropriate dimensions with $\mathrm{G}$ is orthogonal such that the following LMI holds:

$$
\left(\begin{array}{cc}
b\left(X_{L j}-X_{L k}\right)+I-2 \theta X_{L i} & G^{T} A_{i}^{T}+Y^{T} B_{i}^{T}+\theta G^{T}+X_{L i} \\
A_{i} G+B_{i} Y+\theta G+X_{L i} & -G-G^{T}
\end{array}\right)<0
$$

With

$\mathrm{i}=1 \ldots \mathrm{N} ; \quad \mathrm{j}=1 \ldots \mathrm{N} ; \quad \mathrm{k}=1 \ldots \mathrm{N}$

And the control law is given in function of the relaxation matrices as follows:

$$
\mathrm{K}=\mathrm{YG}^{-1}
$$

Proof:

Simultaneous multiplication of (76) by ${ }^{\alpha_{i}}, \sigma_{j}$ and $\beta_{\mathrm{k}}$ gives:

$$
\left(\begin{array}{cc}
b\left(\sigma_{j} X_{L j}-\beta_{k} X_{L k}\right)+I-2 \theta \alpha_{i} X_{L i} & G^{T} \alpha_{i} A_{i}^{T}+Y^{T} \alpha_{i} B_{i}^{T}+\theta G^{T}+\alpha_{i} X_{L i} \\
\alpha_{i} A_{i} G+\alpha_{i} B_{i} Y+\theta G+\alpha_{i} X_{L i} & -G-G^{T}
\end{array}\right)<0
$$

Summing for $\mathrm{i}=1 \ldots \mathrm{N} ; \mathrm{j}=1 \ldots \mathrm{N}$ and $\mathrm{k}=1 \ldots \mathrm{N}$, we deduce the following expression:

$$
\left(\begin{array}{ll}
\mathrm{M}_{11} & \mathrm{M}_{12} \\
\mathrm{M}_{21} & \mathrm{M}_{22}
\end{array}\right)<0
$$

With:

$$
\begin{aligned}
& \mathrm{M}_{11}=\mathrm{b}\left(\mathrm{X}_{\mathrm{L}}(\sigma(\mathrm{t}))-\mathrm{X}_{\mathrm{L}}(\beta(\mathrm{t}))\right)+\mathrm{I}-2 \theta \mathrm{X}_{\mathrm{L}}(\alpha(\mathrm{t})) \\
& \mathrm{M}_{12}=\mathrm{G}^{\mathrm{T}} \mathrm{A}(\alpha(\mathrm{t}))^{\mathrm{T}}+\mathrm{Y}^{\mathrm{T}} \mathrm{B}(\alpha(\mathrm{t}))^{\mathrm{T}}+\theta \mathrm{G}^{\mathrm{T}}+\mathrm{X}_{\mathrm{L}}(\alpha(\mathrm{t})) \\
& \mathrm{M}_{21}=\mathrm{A}(\alpha(\mathrm{t})) \mathrm{G}+\mathrm{B}(\alpha(\mathrm{t})) \mathrm{Y}+\theta \mathrm{G}+\mathrm{X}_{\mathrm{L}}(\alpha(\mathrm{t})) \\
& \mathrm{M}_{22}=-\mathrm{G}-\mathrm{G}^{\mathrm{T}}
\end{aligned}
$$

Assume that there exists a symmetric positive definite $\mathrm{P}(\alpha(\mathrm{t}))$ that has polytopic dependence on the time dependent parameter $\alpha(\mathrm{t})$ such as:

$$
\begin{aligned}
\mathrm{X}_{\mathrm{L}}(\alpha(\mathrm{t}))=\mathrm{G}^{\mathrm{T}} \mathrm{P}(\alpha(\mathrm{t})) \mathrm{G} \\
\Rightarrow \dot{\mathrm{X}}_{\mathrm{L}}(\alpha(\mathrm{t}))=\mathrm{G}^{\mathrm{T}} \dot{\mathrm{P}}(\alpha(\mathrm{t})) \mathrm{G}
\end{aligned}
$$

In this case, based on the expression of Lyapunov matrix's derivative (73), the time derivative of $X_{L}(\alpha(t))$ is obtained as follows

$$
\begin{aligned}
\dot{\mathrm{X}}_{\mathrm{L}}(\alpha(\mathrm{t})) & =\mathrm{b}\left(\mathrm{G}^{\mathrm{T}}\left(\mathrm{P}(\sigma(\mathrm{t})) \mathrm{G}-\mathrm{G}^{\mathrm{T}} \mathrm{P}(\beta(\mathrm{t})) \mathrm{G}\right)\right. \\
& =\mathrm{G}^{\mathrm{T}}(\mathrm{b}(\mathrm{P}(\sigma(\mathrm{t}))-\mathrm{P}(\beta(\mathrm{t})))) \mathrm{G} \\
& =\mathrm{G}^{\mathrm{T}} \dot{\mathrm{P}}(\alpha(\mathrm{t}) \mathrm{G}
\end{aligned}
$$

Also, by considering that $\mathrm{G}$ is orthogonal, the following assumption holds:

$\mathrm{G}^{\mathrm{T}} \mathrm{G}=\mathrm{I}(82)$

This allows replacing the identity matrix in (79) as in (82). $\mathrm{Y}$ and $\mathrm{X}_{\mathrm{L}}(\alpha(\mathrm{t}))$ are respectively replaced as in (77) and (80). Hence, the LMI (79) is equivalent to (83):

$\left(\begin{array}{ll}\mathrm{N}_{11} & \mathrm{~N}_{12} \\ \mathrm{~N}_{21} & \mathrm{~N}_{22}\end{array}\right)<0$

With:

$$
\begin{aligned}
& \mathrm{N}_{11}=\mathrm{G}^{\mathrm{T}} \dot{P}(\alpha(\mathrm{t})) \mathrm{G}+\mathrm{G}^{\mathrm{T}} \mathrm{G}-2 \theta \mathrm{G}^{\mathrm{T}} \mathrm{P}(\alpha(\mathrm{t})) \mathrm{G} \\
& \mathrm{N}_{12}=\mathrm{G}^{\mathrm{T}} \mathrm{A}(\alpha(\mathrm{t}))^{\mathrm{T}}+\mathrm{G}^{\mathrm{T}} \mathrm{K}^{\mathrm{T}} \mathrm{B}(\alpha(\mathrm{t}))^{\mathrm{T}}+\theta \mathrm{G}^{\mathrm{T}}+\mathrm{G}^{\mathrm{T}} \mathrm{P}(\alpha(\mathrm{t})) \mathrm{G} \\
& \mathrm{N}_{21}=\mathrm{A}(\alpha(\mathrm{t})) \mathrm{G}+\mathrm{B}(\alpha(\mathrm{t})) \mathrm{KG}+\theta \mathrm{G}+\mathrm{G}^{\mathrm{T}} \mathrm{P}(\alpha(\mathrm{t})) \mathrm{G} \\
& \mathrm{N}_{22}=-\mathrm{G}-\mathrm{G}^{\mathrm{T}}
\end{aligned}
$$

As previously mentioned, $\mathrm{G}$ is orthogonal which means that it is invertible. Let $D$ be the inverse of $G$. In other words:

$$
\mathrm{D}^{-1}=\mathrm{G}
$$

Hence, the LMI (83) is equivalent to:

$$
\left(\begin{array}{ll}
\mathrm{L}_{11} & \mathrm{~L}_{12} \\
\mathrm{~L}_{21} & \mathrm{~L}_{22}
\end{array}\right)<0
$$

With:

$$
\begin{aligned}
& \mathrm{L}_{11}=\dot{\mathrm{P}}(\alpha(\mathrm{t}))+\mathrm{I}-2 \theta \mathrm{P}(\alpha(\mathrm{t})) \\
& \mathrm{L}_{12}=(\mathrm{A}(\alpha(\mathrm{t}))+\mathrm{B}(\alpha(\mathrm{t})) \mathrm{K}+\theta \mathrm{I})^{\mathrm{T}} \mathrm{D}+\mathrm{P}(\alpha(\mathrm{t})) \\
& \mathrm{L}_{21}=\mathrm{D}^{\mathrm{T}}(\mathrm{A}(\alpha(\mathrm{t}))+\mathrm{B}(\alpha(\mathrm{t})) \mathrm{K}+\theta \mathrm{I})+\mathrm{P}(\alpha(\mathrm{t})) \\
& \mathrm{L}_{22}=-\mathrm{D}-\mathrm{D}^{\mathrm{T}}
\end{aligned}
$$

The equivalence between the LMIs (83) and (85) is obtained through simultaneous right and left multiplication of (85) respectively by $\left[\begin{array}{cc}\mathrm{D}^{-1} & 0 \\ 0 & \mathrm{D}^{-1}\end{array}\right]$ and its transpose. Now, applying the projection lemma (or the elimination lemma) on the LMI (85), the closed loop Lyapunov stability condition in (75) is obtained. In fact, this lemma is common in the 
relaxation of LMIs. It indicates that for a given symmetric matrix $\phi$, and $N$ and $M$ matrix of appropriate dimensions, the following statements are equivalent:

$$
\begin{aligned}
& \phi<0 \quad \& \quad \phi+N M^{T}+M N^{T}<O \\
& \left(\begin{array}{cc}
\phi & M+N D \\
M^{T}+D^{T} N^{T} & -D-D^{\mathrm{T}}
\end{array}\right)<0
\end{aligned}
$$

The analogy between the LMIs (85) and (87) is obtained by considering the following assumptions:

$$
\begin{gathered}
\phi(\alpha(\mathrm{t}))=\dot{\mathrm{P}}(\alpha(\mathrm{t}))+\mathrm{I}-2 \theta \mathrm{P}(\alpha(\mathrm{t})) \\
M=P(\alpha(\mathrm{t})) \\
N=(\mathrm{A}(\alpha(\mathrm{t}))+\mathrm{B}(\alpha(\mathrm{t})) \mathrm{K}+\theta \mathrm{I})^{\mathrm{T}}
\end{gathered}
$$

As previously indicated in the statement of Theorem 1, the choice of the positive scalar $\theta$, should verify the following inequality:

$$
\dot{\mathrm{P}}(\alpha(\mathrm{t}))+\mathrm{I}-2 \theta \mathrm{P}(\alpha(\mathrm{t}))<0
$$

According to the projection lemma, (89) allows deducing that (85) is equivalent to:

$$
\begin{array}{cc} 
& \dot{\mathrm{P}}(\alpha(\mathrm{t}))+\mathrm{I}-2 \theta \mathrm{P}(\alpha(\mathrm{t}))<0 \\
\Rightarrow \quad & \dot{\mathrm{P}}(\alpha(\mathrm{t}))+\mathrm{I}-2 \theta \mathrm{P}(\alpha(\mathrm{t})) \\
& +(\mathrm{A}(\alpha(\mathrm{t}))+\mathrm{B}(\alpha(\mathrm{t})) \mathrm{K}+\theta \mathrm{I})^{\mathrm{T}} \mathrm{P}(\alpha(\mathrm{t})) \\
+\mathrm{P}(\alpha(\mathrm{t}))(\mathrm{A}(\alpha(\mathrm{t}))+\mathrm{B}(\alpha(\mathrm{t})) \mathrm{K}+\theta \mathrm{I})<0
\end{array}
$$

The expansion then the factorization of (90) leads to the closed loop Lyapunov stability condition in (75).

Now the slack variables $X_{L}(\alpha(t)), Y$ and $G$ have to be considered in the formulation of the entire LQR control problem (i.e. in the performance cost function). For this reason, and based on the results of Theorem 1, Theorem 2 states a new LMI formulation of the stabilizing LQR control problem in the case of a parameter dependent Lyapunov function.

\section{Theorem 2:}

The LQR control law (77) stabilizes asymptotically the system (51) in closed loop if it minimizes the performance cost:

$$
\min _{\mathrm{X}_{\mathrm{L}}, \mathrm{X}} \operatorname{Tr}\left(\mathrm{Q}_{\mathrm{w}} \mathrm{X}_{\mathrm{L}}(\alpha(\mathrm{t}))\right)+\operatorname{Tr}(\mathrm{X}(\alpha(\mathrm{t})))
$$

Subject to:

$$
\left(\begin{array}{ll}
\mathrm{L}_{11} & \mathrm{~L}_{12} \\
\mathrm{~L}_{21} & \mathrm{~L}_{22}
\end{array}\right)<0
$$

and:

$$
\left(\begin{array}{cc}
X(\alpha(t)) & R^{1 / 2} Y \\
Y^{T} R^{1 / 2} & G+G^{T}-X(\alpha(t))
\end{array}\right)>0
$$

With the coefficients of (92) are as in (85) and $X(\alpha(t))$ is a positive definite matrix of appropriate dimensions.

Proof:

(92) refers to the newly stated Lyapunov asymptotic stability condition in Theorem 1. (91) and (93) stand for the minimization of the performance cost of the LQR problem. In fact, as in the constant Lyapunov function case, $X(\alpha(t))$ is chosen such that:

$\operatorname{Tr}(\mathrm{X}(\alpha(\mathrm{t})))>\operatorname{Tr}\left(\mathrm{R}^{1 / 2} \mathrm{KP}(\alpha(\mathrm{t})) \mathrm{K}^{\mathrm{T}} \mathrm{R}^{1 / 2}\right)$

Besides, $\operatorname{Tr}(\mathrm{Q} . \mathrm{P}(\alpha(\mathrm{t})))$ in (74) is substituted for $\operatorname{Tr}\left(Q_{w} X_{L}(\alpha(t))\right)$ in (91) in order to involve the new Lyapunov matrix $\mathrm{X}_{\mathrm{L}}(\alpha(\mathrm{t})) \cdot \mathrm{Q}_{\mathrm{w}}$ is a weighting symmetric semi definite positive matrix. In fact, expressing $\mathrm{P}(\alpha(\mathrm{t})$ ) from (80) gives the following equality: $\operatorname{Tr}(\mathrm{Q} . \mathrm{P}(\alpha(\mathrm{t})))=\operatorname{Tr}(\underbrace{\mathrm{QG}^{-\mathrm{T}} \mathrm{X}(\alpha(\mathrm{t}))}_{\mathrm{a}} \mathrm{G}_{\mathrm{b}}^{-1})$. Moreover, the trace operator allows considering that $\operatorname{Tr}(a \times b)=\operatorname{Tr}(b \times a)$. Hence:

$$
\begin{aligned}
\operatorname{Tr}(\mathrm{QP}(\alpha(\mathrm{t}))) & =\operatorname{Tr}(\underbrace{\mathrm{QG}^{-\mathrm{T}} \mathrm{X}_{\mathrm{L}}(\alpha(\mathrm{t}))}_{\mathrm{a}} \mathrm{G}_{\mathrm{b}}^{-1}) \\
& =\operatorname{Tr}\left(\mathrm{G}^{-1} \mathrm{QG}^{-\mathrm{T}} \mathrm{X}_{\mathrm{L}}(\alpha(\mathrm{t}))\right) \\
& =\operatorname{Tr}(\underbrace{\left.\mathrm{G}^{\mathrm{T}} \mathrm{QG} X_{\mathrm{L}}(\alpha(\mathrm{t}))\right)}_{\mathrm{Q}_{\mathrm{w}}}
\end{aligned}
$$

Given that $\mathrm{Q}$ is symmetric and semi definite positive then $\mathrm{G}^{\mathrm{T}} \mathrm{QG}$ holds the same characteristics. In the rest of the problem formulation, $\mathrm{Q}_{\mathrm{w}}=\mathrm{G}^{\mathrm{T}} \mathrm{QG}$ is considered as the weighting matrix of the focused LQR law. Now (94) is equivalent to:

$$
\mathrm{X}(\alpha(\mathrm{t}))-\mathrm{R}^{1 / 2} \mathrm{~K}_{\mathrm{X}_{\mathrm{L}}(\alpha(\mathrm{t}))}^{\mathrm{G}^{\mathrm{T}} \mathrm{P}(\alpha(\mathrm{t})) \mathrm{G}} \mathrm{K}^{\mathrm{T}} \mathrm{R}^{1 / 2}>0
$$

Applying Schur complement on (96) gives:

$$
\left(\begin{array}{cc}
\mathrm{X}(\alpha(\mathrm{t})) & \mathrm{R}^{1 / 2} \mathrm{YG}^{-1} \\
\mathrm{G}^{-\mathrm{T}} \mathrm{Y}^{\mathrm{T}} \mathrm{R}^{1 / 2} & \mathrm{X}_{\mathrm{L}}(\alpha(\mathrm{t}))^{-1}
\end{array}\right)>0
$$

The relaxation of (97) is obtained by simultaneous right and left multiplication by respectively $\left(\begin{array}{ll}1 & 0 \\ 0 & G\end{array}\right)>0$ and its transpose. This gives:

$$
\left(\begin{array}{cc}
\mathrm{X}(\alpha(\mathrm{t})) & \mathrm{R}^{1 / 2} \mathrm{Y} \\
\mathrm{Y}^{\mathrm{T}} \mathrm{R}^{1 / 2} & \mathrm{G}^{\mathrm{T}} \mathrm{X}_{\mathrm{L}}(\alpha(\mathrm{t}))^{-1} \mathrm{G}
\end{array}\right)>0
$$

In addition, based on the results of [32], the following inequality is considered for the simplification of the parameter $\mathrm{G}^{\mathrm{T}} \mathrm{X}_{\mathrm{L}}(\alpha(\mathrm{t}))^{-1} \mathrm{G}$ in (98): 
$\mathrm{G}^{\mathrm{T}} \mathrm{X}_{\mathrm{L}}(\alpha(\mathrm{t}))^{-1} \mathrm{G} \geq \mathrm{G}+\mathrm{G}^{\mathrm{T}}-\mathrm{X}(\alpha(\mathrm{t}))$

Then the LMI (98) can be replaced by (93).

As in (70), (71) and (72), this work is based on the formulation of (91), (92) and (93) in the $\mathrm{N}$ vertices of the polytope containing the admissible variations of the system dynamics. In each vertices, the studied control problem is formulated as follows:

$$
\min _{X_{\mathrm{Li}}, X_{\mathrm{i}}} \operatorname{Tr}\left(\mathrm{Q}_{\mathrm{w}} \mathrm{X}_{\mathrm{Li}}\right)+\operatorname{Tr}\left(\mathrm{X}_{\mathrm{i}}\right)
$$

Subject to:

$$
\left(\begin{array}{cc}
b\left(X_{\mathrm{Lj}}-\mathrm{X}_{\mathrm{Lk}}\right)+\mathrm{I}-2 \theta \mathrm{X}_{\mathrm{Li}} & \mathrm{G}^{\mathrm{T}} \mathrm{A}_{\mathrm{i}}^{\mathrm{T}}+\mathrm{Y}^{\mathrm{T}} \mathrm{B}_{\mathrm{i}}^{\mathrm{T}}+\theta \mathrm{G}^{\mathrm{T}}+\mathrm{X}_{\mathrm{Li}} \\
\mathrm{A}_{\mathrm{i}} \mathrm{G}+\mathrm{B}_{\mathrm{i}} \mathrm{Y}+\theta \mathrm{G}+\mathrm{X}_{\mathrm{Li}} & -\mathrm{G}-\mathrm{G}^{\mathrm{T}}
\end{array}\right)<0
$$

And:

$$
\left(\begin{array}{cc}
X_{i} & R^{1 / 2} Y \\
Y^{T} R^{1 / 2} & G+G^{T}-X_{i}
\end{array}\right)>0
$$

Thus, the feasibility of the abovementioned LMIs will give the control law gain $\mathrm{K}_{\mathrm{P}_{\mathrm{var}}}$ as in (77) for the case of a parameter dependent Lyapunov function.

\section{Silulation Results}

In this section, the simulation results of the system (51) without and with the controller are presented. The control problem for both constant and parameter dependent Lyapunov matrix cases is formulated in the extrema of the convex polytope containing the uncertainties variation ranges. The YALMIP resolution of the problem is performed and simulation results are discussed. Then control performances are studied. The dynamic matrices of the system (51) are given as follows:

$$
\begin{aligned}
\mathrm{A}_{\mathrm{e}}((\alpha(\mathrm{t})) & =\alpha_{1}(\mathrm{t})\left(\begin{array}{cc}
-54.9377 & 94.3593 \\
-94.3593 & -54.9377
\end{array}\right) \\
& +\alpha_{2}(\mathrm{t})\left(\begin{array}{rrr}
-54.9377 & -94.0407 \\
94.0407 & -54.9377
\end{array}\right) \\
\mathrm{B}_{\mathrm{e}}((\alpha(\mathrm{t})) & =\alpha_{1}(\mathrm{t})\left(\begin{array}{cccc}
0 & 0 & 4010 & 0 \\
0 & 44904 & 0 & 4010
\end{array}\right) \\
& +\alpha_{2}(\mathrm{t})\left(\begin{array}{cccc}
0 & 0 & 4010 & 0 \\
0 & 83393 & 0 & 4010
\end{array}\right)
\end{aligned}
$$

The LMIs resolution of (70), (71) and (72) leads to the following $\mathrm{K}_{\text {Pconst }}$ control law:

$$
\mathrm{K}_{\text {Pconst }}=\left[\begin{array}{lr}
0 & 0 \\
0.0005 & -0.0253 \\
-0.0248 & 0.0019 \\
0.0019 & -0.0019
\end{array}\right]
$$

With a performance index cost of:

$$
\mathrm{J}_{\text {pconst }}=6.6833 .10^{-6}(106)
$$

While the resolution of the LMIs (91), (92) and (93) with $\mathrm{b}=1$ and $\theta=403$ gives the following $\mathrm{P}$-variable control law:

$$
\mathrm{K}_{\text {Pvar }}=\left[\begin{array}{cc}
0 & 0 \\
0.0048 & 0.0008 \\
-0.0866 & -0.0002 \\
0.0769 & -0.0734
\end{array}\right]
$$

then the performance index in this case is:

$$
\mathrm{J}_{\mathrm{Pvar}}=1.7663 .10^{-4}
$$

\section{A. LQR Control of the Error Model: $\mathrm{K}_{\mathrm{Pconst}}$ Compared to $\mathrm{K}_{\mathrm{Pvar}}$ :}

The closed loop state visualization of (51) without LQR control is provided in Fig. 5 (The NC symbol depicts the NonControlled magnitudes while the $\mathrm{CL}$ one refers to the Cloosed Loop system). It shows that the state vector components converge to finite values within a finite time. The error between the measured magnitudes and the desired ones $e(\alpha(t))$ reaches zero for the direct components within a considerable time delay while it is nonzero for the quadratic ones.

The simulation of (51) with the feedback law (72) is depicted in Fig. 6. The NC and CL symbols in the figures denote respectively the non-controlled and the controlled system cases.
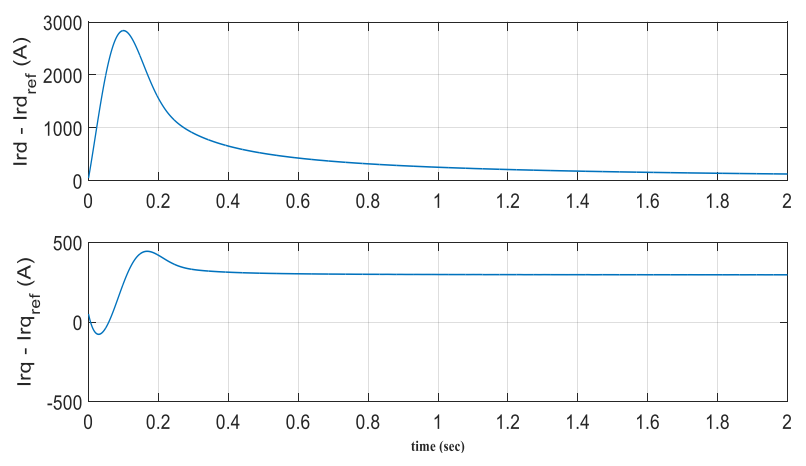

Fig. 5. State Space Visualization of the Error Model.
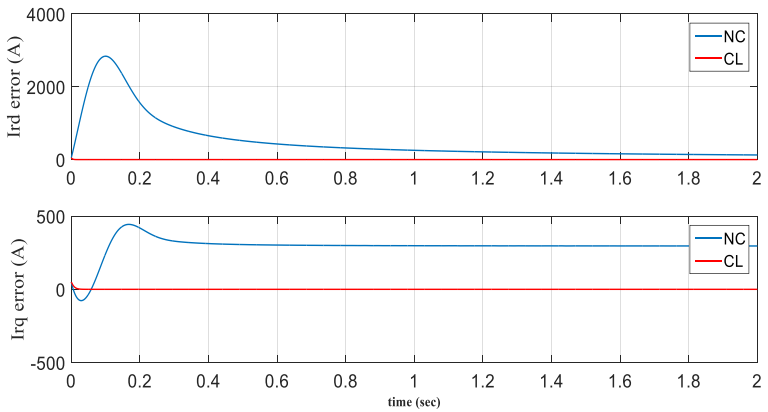

Fig. 6. Ird and Irq Errors of NC System and in CL for Kpconst. 
As the simulation indicated, the obtained controller provides a zero error between the measured and the desired rotor current magnitudes for all the admissible values of $\alpha_{1}(t)$ and $\alpha_{2}(t)$. In addition, the controller time response is considerably thin. We notice that the already given results are available for any chosen references values since the controller synthesis is independent from the desired inputs. This implies that $\mathrm{K}_{\text {Pconst }}$ is an invariant robust control law that maintains the same tracking performances for all the admissible variations of the uncertainty. The closed loop state visualization of (51) with the feedback law $\mathrm{K}_{\mathrm{Pvar}}$ is given in Fig. 7.

Fig. 8 shows that the P-variable controller (107) gives better tracking performances for the quadratic component of the rotor current. In addition, from (106) and (108), it can be deduced that even the robust LQR controller based on a parameter varying Lyapunov candidate matrix gives a small performance index cost $\mathrm{J}$.

Fig. 9 shows that compared to the LQR controller obtained from the predefined Matlab function, both the proposed control laws $\mathrm{K}_{\mathrm{Pconst}}$ and $\mathrm{K}_{\mathrm{P} \text { var }}$ give better results in terms of time response and zero steady state error. This can be explained by the fact that the predefined controller is calculated in one operating point and not in the whole operating range of the system. However, the approach we give not only considers the Lyapunov stability theory as a constraint of the LMI LQR tracking problem formulation but also derives a static controller that holds for all the admissible uncertainty's variation range.
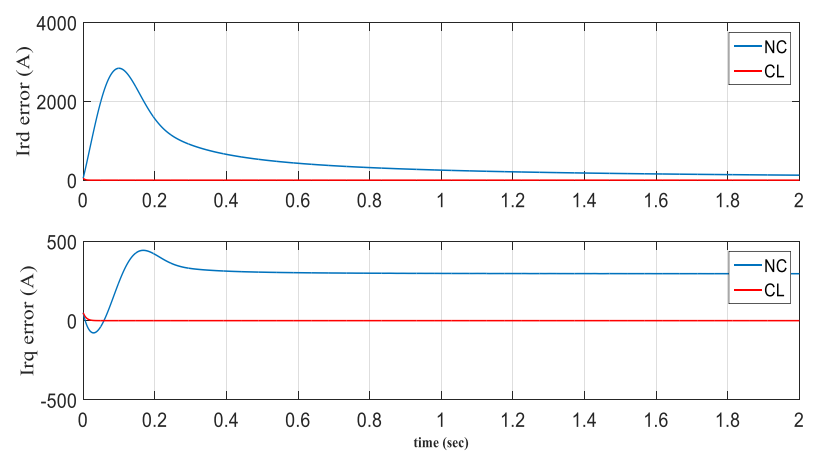

Fig. 7. Ird and Irq Errors in NC System and in CL for Kpvar.
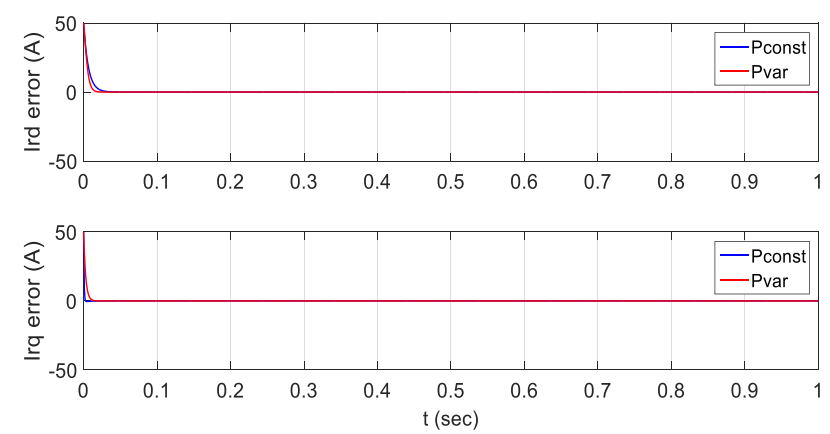

Fig. 8. Kpconst Vs Kpvar.
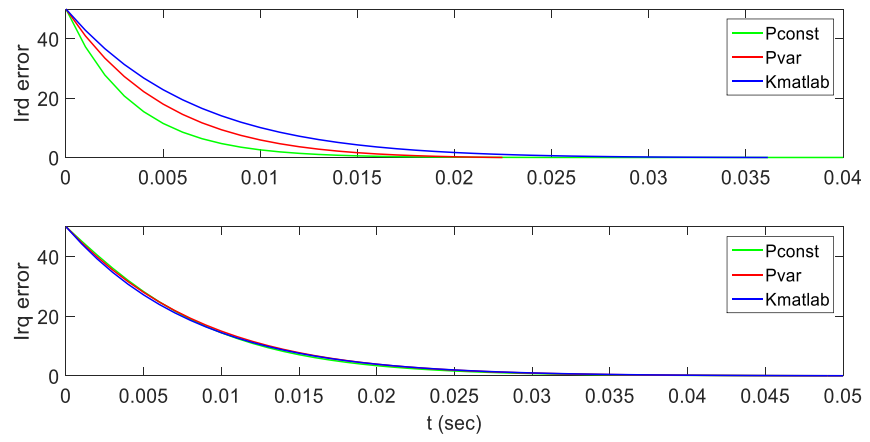

Fig. 9. Ird and Irq Errors in CL System for Kpconst, Kpvar and Kmatlab.

From these simulation results, one can deduce that the variable Lyapunov candidate matrix based regulator, which we obtained through a new LMI formulation of the Lyapunov stability condition, gives an optimal index of the control cost. In addition, the robust stability and tracking performances of the regulator are validated on the error model (51). $\mathrm{K}_{\mathrm{P} \text { var }}$ is then acknowledged for active and reactive power tracking of the considered WECS. The main feature of the proposed approach over others is that it is non-conservative. This means that the feasibility of the problem is not limited to the existence of a unique constant Lyapunov function. It is rather conditioned by the existence of the sum of a set of Lyapunov functions existing in each vertice of the convex polytope containing the system variations. In the next subsection, the validation of the already established control law is carried out on the DFIG model (21).

\section{B. Robust State Tracking of the LPV DFIG System}

In the previous section, we obtained the robust LQR controller for (51) that forces the error between the desired and the measured current components values towards zero in order to achieve active and reactive power tracking of the WECS based on (24) and (25). The robustness of the presented control law is verified as it is obtained through an LMI approach based on Lyapunov candidate matrix that has the same dynamics as well as the state space system matrix. The objective of this section is to validate the controller tracking performances on the studied system through the accomplished Matlab emulator. By going back to (53), we notice that the obtained control gain, holds for the DFIG error model (51). However, the main concern of this paper is to find the state feedback control law that holds for the accurate DFIG model (21). Therefore, in order to define the control law that holds for the wind turbine generator model, the adjustment (52) must be applied. $U_{\text {ref }}$ is deduced from equations (32), (33) and the value of $X_{\text {ref }}$ under steady state assumption. However, in this case, (32) and (33) depend on the optimal value of $\omega_{\mathrm{r}} \cdot \omega_{r_{\text {ref }}}$ is generated by a Maximum Power Point control system based on the results of Fig. 10 and 11. The MPPT control aims at impelling the system to operate at the optimal value of $\omega_{r_{-} \text {ref }}$ for each admissible value of wind velocity and blade pitch angle. 


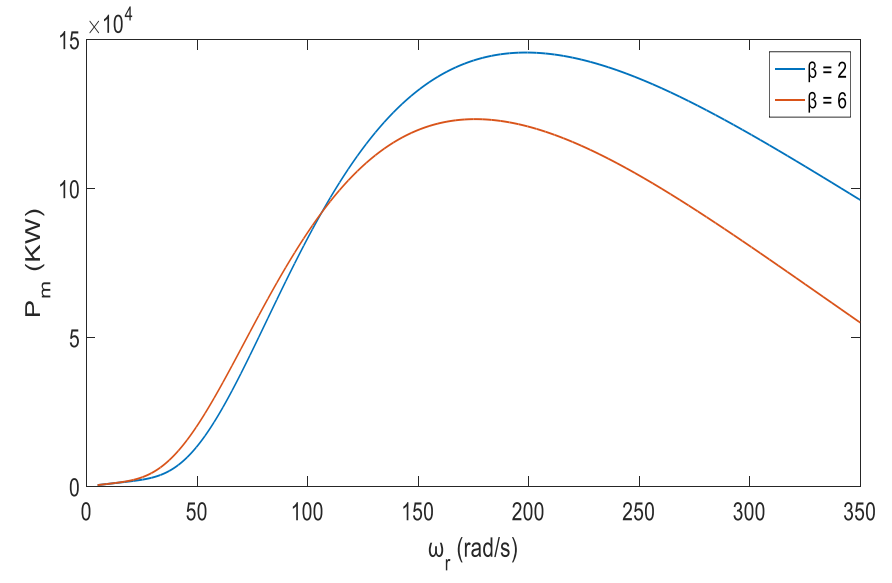

Fig. 10. Maximum Power Points for Pitch Variable and V=10 m/s.

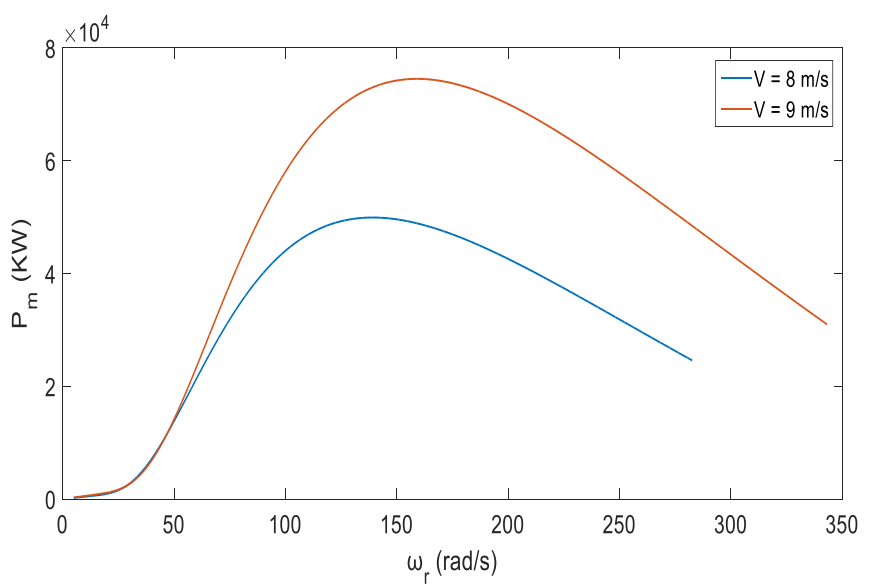

Fig. 11. Maximum Power Points for Variable Wind Speed and $\beta=2$.

C. Control Robustness Verification for Different References Values for the Entire Varying Parameter Admissible Range

1. $\underline{\underline{\text { Case 1: }}} \mathrm{P}_{\text {sref }}=2 \cdot 10^{5} \mathrm{~W} \& \mathrm{Q}_{\text {sref }}=0.5 \cdot 10^{5}$ var

Fig. 12 and 13 show respectively the simulation of $I_{r d}$ and $I_{r q}$ in closed loop functioning. The blue line depicts the closed loop system. The red line depicts the reference signals.

Fig. 14 and 15 show respectively the tracking results of $\mathrm{P}_{\mathrm{s}}$ and $\mathrm{Q}_{\mathrm{s}}$.

2. $\underline{\text { Case 2: }} \mathrm{P}_{\text {sref }}=1.10^{5} \mathrm{~W} \& \mathrm{Q}_{\text {sref }}=0.10^{5}$ var

The simulations of the previous subsection are respectively performed in this paragraph in order to highlight the same tracking performances for a randomly chosen active and reactive power references.

Simulation results of direct and quadratic rotor currents, $P_{s}$ and $\mathrm{Q}_{\mathrm{s}}$ are respectively given in Fig. 16, 17, 18 and 19.

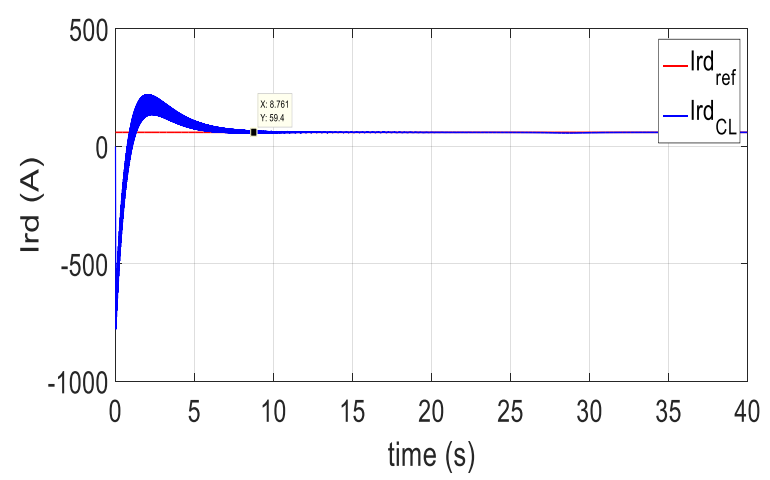

Fig. 12. Ird Tracking Result.

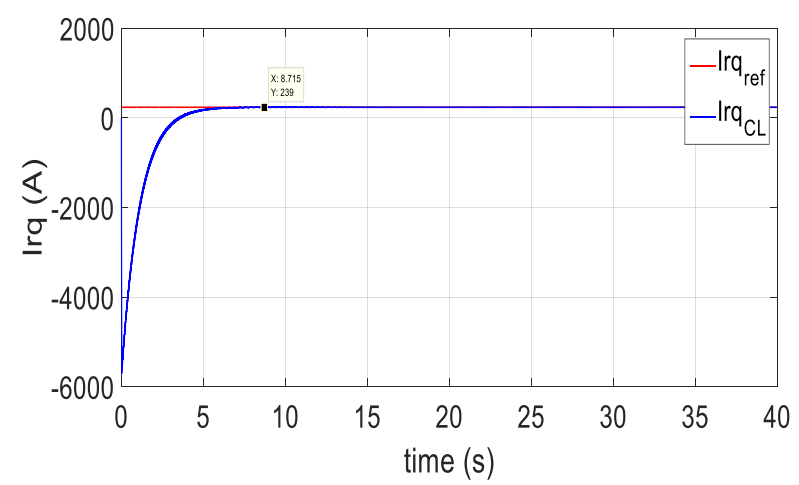

Fig. 13. Irq Tracking Result.

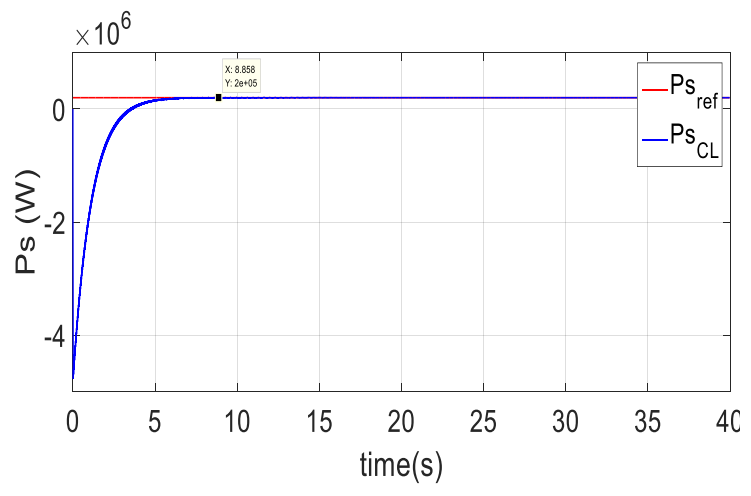

Fig. 14. Ps Tracking Result.

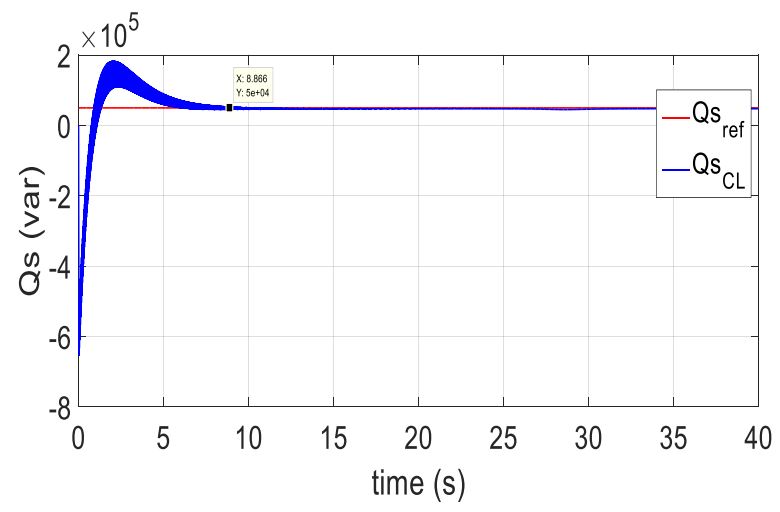

Fig. 15. Qs Tracking Result. 


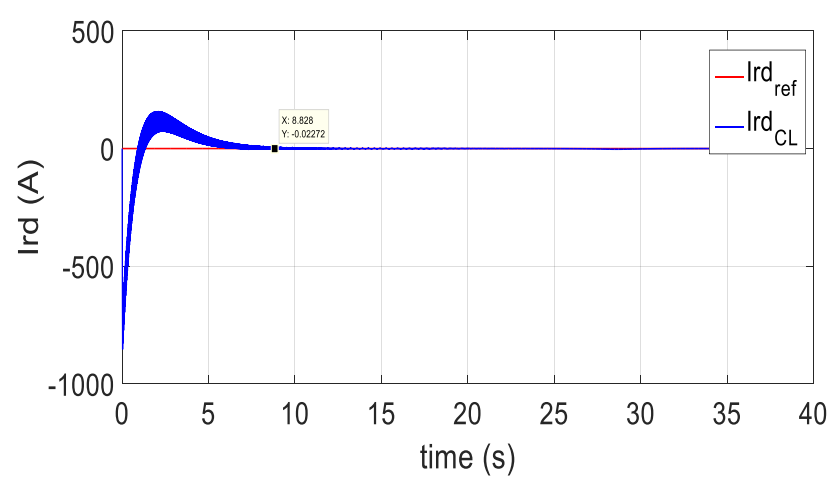

Fig. 16. Ird Tracking Result

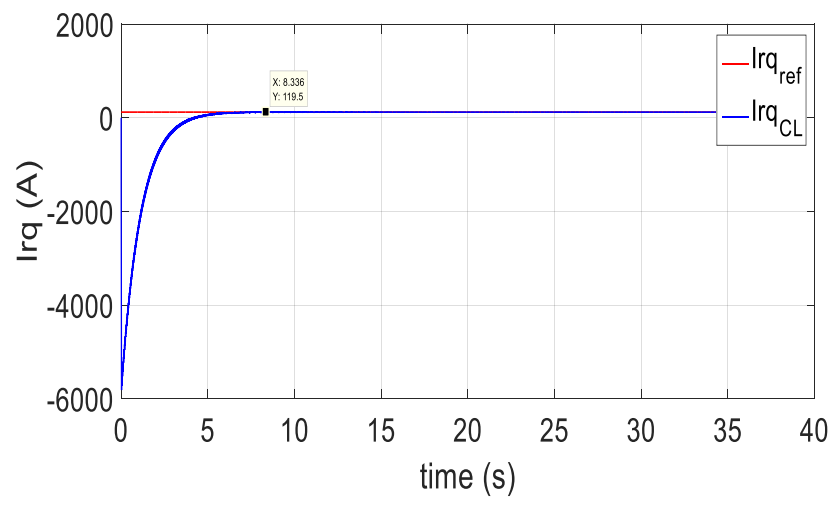

Fig. 17. Irq Tracking Result

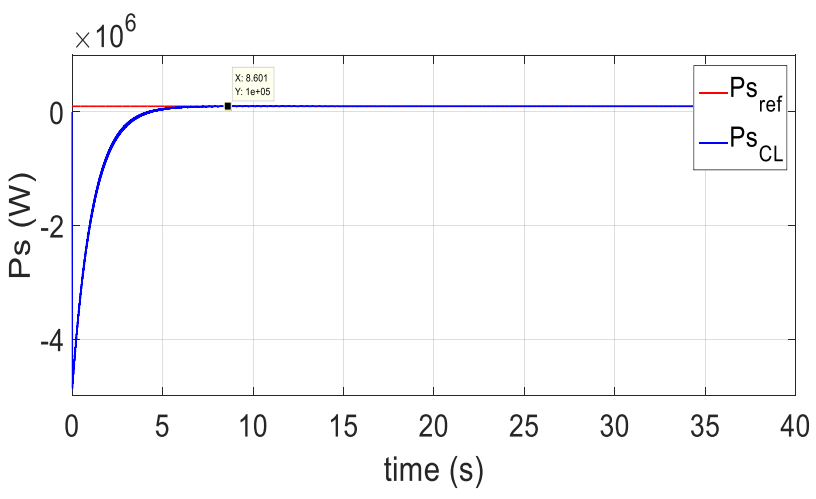

Fig. 18. Active Power Tracking Result

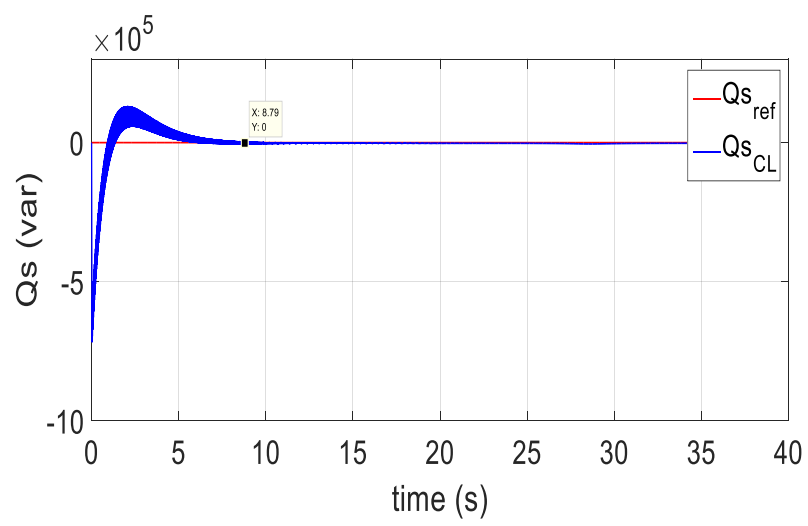

Fig. 19. Reactive Power Tracking Result

\section{CONCLUSION}

The main concern of this work was the LQR robust static state tracking control of a polytopic LPV DFIG model based on an LMI approach. Two major contributions were presented in this paper. First, a new formulation of the asymptotic stability condition of Lyapunov theory was established. Then, a new LMI formulation of the LQR state control problem based on a time dependent Lyapunov function was provided. The comparison between a controller based on a quadratic Lyapunov function and a controller with a time dependent Lyapunov function shows that the latter gives more freedom degrees to the control synthesis. Robustness of the controller is validated over all the admissible range of the system time varying parameter. Simulation results demonstrated also that the proposed non-conservative regulator gave good tracking performances for different active and reactive power references. This work is a step that can be taken further. The obtained results can be evaluated on a real-world emulator. Moreover, it can be extended to a case of a Low Voltage Ride Through (LVRT) where the grid voltage is considered as the time varying parameter. Future works can also investigates the possibility to extend the current results for general non-linear systems based on dynamic models.

\section{REFERENCES}

[1] Richardson, R. D.; Mcnerney, G. M.: Wind Energy-Systems, Ieee, vol. 81, no. 3, pp. 378-389, 1993.

[2] World wind energy association: World wind energy report 2008.

[3] Manwell, J. F.; McGowan, J.; Rogers, A.: Wind Energy Explained Theory, Design and Applications. United Kingdom, 2009.

[4] Kammoun, S. ; Contribution à la commande des systèmes de puissance en vue de l'intégration de l'énergie éolienne dans le réseau. April 2016.

[5] Carlin, P. W. ; Laxson, A. S.; Muljadi, E. B. : The history and state of the art of variable-speed wind turbine technology, Wind Energy, vol. 6, pp. 129-159, Apr. 2003.

[6] Fletcher, J. ; Yang, J.: Introduction to Doubly-Fed Induction Generator for Wind Power Applications, University of Strathclyde, Glasgow United Kingdom, 2010.

[7] Mwaniki, J.; Lin, H.; Dai, Z.: A Condensed Introduction to the Doubly Fed Induction Generator Wind Energy Conversion Systems, Journal of Engineering, June 2017. https://doi.org/10.1155/2017/2918281

[8] Zhang, L.; Cai, Xu; Guo, J.: Simplified Input-Output Linearizing and Decoupling Control of Wind Turbine Driven Doubly-Fed Induction Generators, IEEE IPEMC, pp. 632-637, 2009.

[9] Nadour, M. ; Essadki, A. ; Nasser, T. : Comparative Analysis between PI \& Backstepping Control Strategies of DFIG Driven by Wind Turbine, International Journal of Renewable Energy Research-IJRER, pp. 13071316, 2017.

[10] Djoudi, A.; Bacha, S. ;Hussein, I.E. ; Rekioua, T. : Sliding mode control of DFIG powers in the case of unknown flux and rotor currents with reduced switching frequency, International Journal of Electrical Power \& Energy Systems, March 2018, https://doi.org/10.1016/.ijepes.2017.10.009

[11] Kammoun, S., Sallem, S. \& Kammoun, M.B.A. Arab J Sci Eng (2017) 42: 5083. https://doi.org/10.1007/s13369-017-2606-z

[12] Bossoufi, B.; Karim, M.\& al.; ElHafyani, M.L.: Backstepping control of DFIG generators for wide-range variable-speed wind turbines, https://doi.org/10.1504/IJAAC.2014.063359

[13] Bekakra, Y.; B.Atrous, J.: DFIG sliding mode control fed by back-toback PWM converter with DC-link voltage control for variable speed wind turbine, https://doi.org/10.1007/s11708-014-0330-x

[14] Alper Eker S.; Nikolaou, M.: Linear control of nonlinear systems: Interplay between nonlinearity and feedback, AIChE Journal, September 2002, https://doi.org/10.1002/aic.690480912 
[15] Rossiter, J.A.; Pluymers, B.: The potential of interpolation for simplifying predictive control and application to LPV systems, University of Sheffield, September 2007.

[16] Pham, T.; Nam, Y.; Kim, H.; Son, J.: LQR Control for a Multi-MW Wind Turbine, International Journal of Mechanical, Aerospace, Industrial, Mechatronic and Manufacturing Engineering, Vol:6, No:2, November 2012.

[17] Kedjar, B.; Haddad, K.A.: LQR with integral action applied to a wind energy conversion system based on doubly fed induction generator, Electrical and Computer Engineering (CCECE), 2011, http://dx.doi.org/10.1109/CCECE.2011.6030548

[18] Semaria, R.;Julian, P.; Jairo, E.: PI and LQR controllers for Frequency Regulation including Wind Generation, International Journal of Electrical and Computer Engineering (IJECE) 2018, http://doi.org/10.11591/ijece.v8i5.pp\%25p.

[19] Ravi, B.; Kalyan, Ch.: Mathematical modeling and control of DFIGbased wind energy system by using optimized linear quadratic regulator weight matrices, International Transactions on Electrical Energy Systems, July 2017, http://doi.org/10.1002/etep.2416.

[20] Ghafouri, M.; Karaagac, U.; Karimi, H.; Jensen, S.; Mahseredjian, J.; Faried, S.O.: An LQR Controller for Damping of Subsynchronous Interaction in DFIG-Based Wind Farms, IEEE Transactions on Power Systems, http://doi.org/10.1109/TPWRS.2017.2669260.

[21] Khajeh, A.;Ghazi, R.: GA-Based Optimal LQR Controller to Improve LVRT Capability of DFIG Wind Turbines, International Journal of Electronics and Electrical Engineering. September 2013, vol. 9, no. 3, pp. 167-176.,2013.

[22] Bachir, K.; Kamal, A.H.: LQR with integral action applied to a wind energy conversion system based on doubly fed induction, 24th Canadian Conference on Electrical and Computer Engineering(CCECE), September 2011, http://doi.org/10.1109/CCECE.2011.6030548.

[23] Wang, C.; Weiss, G.: Linear parameter varying control of a doubly fed induction generator based wind turbine with primary grid frequency support, International Journal of Robust Nonlinear Control, September 2014 http://doi.org/10.1002/rnc.3228.
[24] Aouani, N.; Salhi, S.; Ksouri, M.: H2 analysis for LPV systems by parameter-dependent Lyapunov functions, IMA Journal of Mathematical Control and Information (2012), http://dx.doi.org/10.1093/imamci/dnr026

[25] Abdullah M.A; Yatim A.H.M; Tan C.W,;Saidur R:A review of maximum power point tracking algorithms for wind energy systems, Renewable and Sustainable Energy Reviews, 2012.

[26] Rafikov, M..; Balthazar, J.M.; Tusset, Â.M.: An optimal linear control design for nonlinear systems, Journal of the Brazilian Society of Mechanical Sciences and Engineering, October/December 2008, http://dx.doi.org/10.1590/S1678-58782008000400002

[27] D’Azzo, J. ; Houpis, C, Linear control systems, analysis and design, conventional and modern. Series in Electrical and Computer Engineering. McGraw-Hill, New York, 1995.

[28] Feron, E. ; Balakrishnan, V.; Boyd, S. ; El Ghaoui, L. Numerical methods for H2 related problems, American Control Conference, 1992.

[29] Kammoun, S.; Marrekchi, A.; Sallem, S.; Kammoun, MBA.: Transient Stability Analysis during an Improved Coupling Procedure for an Induction Generator Based Wind Generation System to the Grid, International Journal of Modern Nonlinear Theory and Application, July, 2014,https://doi.org/10.4236/ijmnta.2014.33010.

[30] Salhi, S. ; Aouani N. ; Salhi, S. : LPV Polytopic modelling and stability analysis of a DFIG for a Wind Energy Conversion System based on LMI approach, GECS'2017, March 2017.

[31] Olalla, C.; Leyva, R.;.El.Aroudi, A; Queinnec, I.: Robust LQR Control for PWM Converters: An LMI Approach, IEEE Transactions on industrial electronics, July 2009. http://doi.org/10.1109/TIE.2009.2017556.

[32] Geromel, J. C. ; de Oliveira M. C. ; Bernussou, J. : Robust Filtering of Discrete-Time Linear Systems with Parameter Dependent Lyapunov Functions, SIAM Journal on Control and Optimization. https://doi.org/10.1137/S0363012999366308. 